\title{
Sensory Coding and Sensitivity to Local Estrogens Shift during Critical Period Milestones in the Auditory Cortex of Male Songbirds
}

\author{
DDaniel M. Vahaba, ${ }^{1}$ ํ) Matheus Macedo-Lima, ${ }^{1,4}$ and ${ }^{-}$Luke Remage-Healey ${ }^{1,2,3}$
}

DOI:http://dx.doi.org/10.1523/ENEURO.0317-17.2017

${ }^{1}$ Neuroscience and Behavior Graduate Program, ${ }^{2}$ Center for Neuroendocrine Studies, University of Massachusetts, Amherst, MA 01003, ${ }^{3}$ Department of Psychological \& Brain Sciences, University of Massachusetts, Amherst, MA 01003, and ${ }^{4}$ CAPES Foundation, Ministry of Education of Brazil, 70040-020, Brazil DF

\section{Visual Abstract}

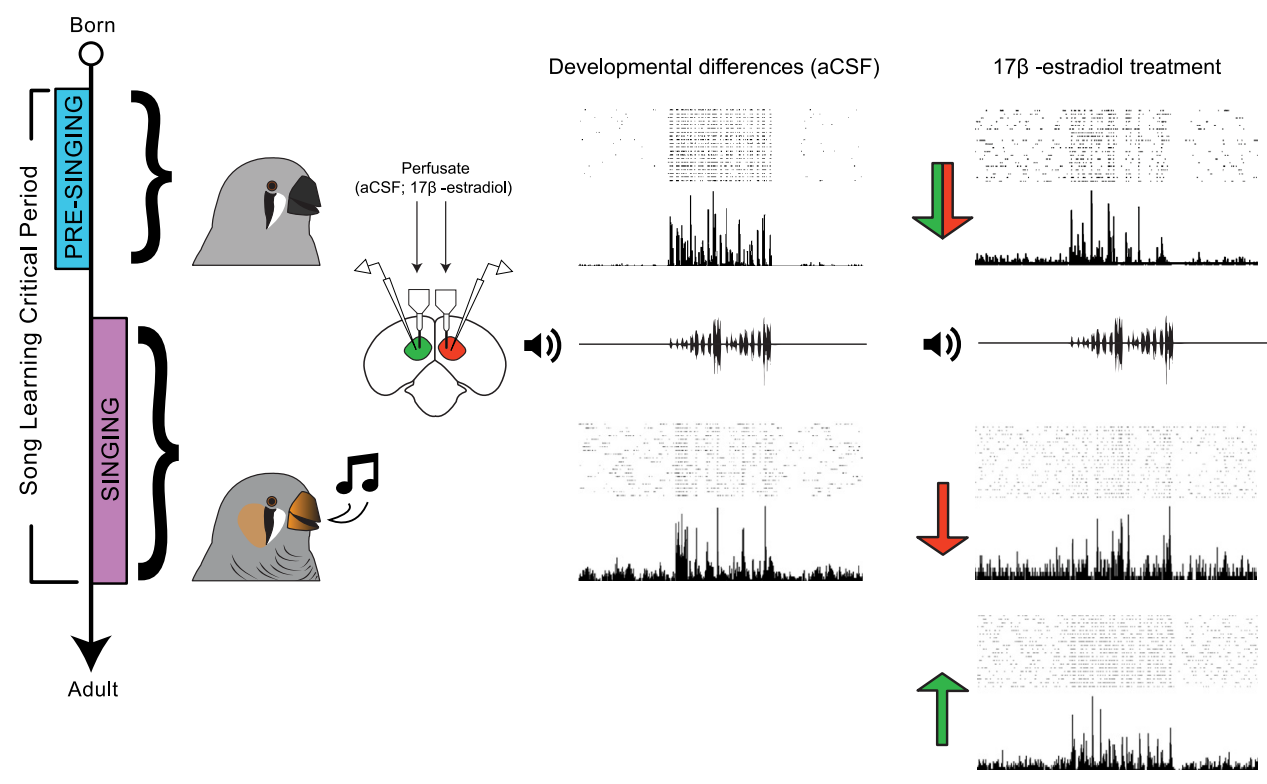

\section{Significance Statement}

Vocal communication, such as language and birdsong, is learned during an age-limited critical period early in development. Initially, infants and songbirds exclusively listen to memorize their native tongue before producing nascent vocalizations. We show that the transition from pre-singing to vocalizing in developing songbirds is accompanied by a large shift in auditory gain and coding in cortical neurons. Further, whereas estrogens generally improve hearing in adulthood, we found that brain estrogens either enhanced or diminished auditory responsiveness depending on both critical period phase and cerebral hemisphere. Our findings therefore highlight a neural transition in auditory processing and lateralized hormone sensitivity at a key stage in development, and similar mechanisms could be relevant for speech processing and language acquisition in humans. 


\begin{abstract}
Vocal learning occurs during an experience-dependent, age-limited critical period early in development. In songbirds, vocal learning begins when presinging birds acquire an auditory memory of their tutor's song (sensory phase) followed by the onset of vocal production and refinement (sensorimotor phase). Hearing is necessary throughout the vocal learning critical period. One key brain area for songbird auditory processing is the caudomedial nidopallium (NCM), a telencephalic region analogous to mammalian auditory cortex. Despite NCM's established role in auditory processing, it is unclear how the response properties of NCM neurons may shift across development. Moreover, communication processing in NCM is rapidly enhanced by local $17 \beta$-estradiol (E2) administration in adult songbirds; however, the function of dynamically fluctuating $\mathrm{E}_{2}$ in NCM during development is unknown. We collected bilateral extracellular recordings in NCM coupled with reverse microdialysis delivery in juvenile male zebra finches (Taeniopygia guttata) across the vocal learning critical period. We found that auditory-evoked activity and coding accuracy were substantially higher in the NCM of sensory-aged animals compared to sensorimotor-aged animals. Further, we observed both age-dependent and lateralized effects of local $E_{2}$ administration on sensory processing. In sensory-aged subjects, $E_{2}$ decreased auditory responsiveness across both hemispheres; however, a similar trend was observed in age-matched control subjects. In sensorimotor-aged subjects, $\mathrm{E}_{2}$ dampened auditory responsiveness in left NCM but enhanced auditory responsiveness in right NCM. Our results reveal an age-dependent physiological shift in auditory processing and lateralized $\mathrm{E}_{2}$ sensitivity that each precisely track a key neural "switch point" from purely sensory (pre-singing) to sensorimotor (singing) in developing songbirds.
\end{abstract}

Key words: Auditory cortex; communication processing; critical periods; lateralization; neuroestrogens; songbird

\section{Introduction}

Critical periods are windows of heightened experiencedependent neuroplasticity in which early sensory input shapes neural circuits and behaviors. Critical period research has historically focused on how sensory exposure or deprivation drive cortical and behavioral shifts in development (Lorenz, 1937; Wiesel and Hubel, 1963; Bolhuis, 1991; Hensch, 2005). Some critical periods for learned behaviors, such as vocal communication, shift from being purely sensory (auditory) to an active sensorimotor phase (vocal production, exploration, and refinement; Kuhl, 2010). Such behavioral transitions are likely accompanied by neural changes in sensory processing. Relatively little is known about factors that change during vocal communication learning, however, as experience-dependent learned vocal communication (vocal learning) is found in only a handful of animal species, including humans and songbirds (Petkov and Jarvis, 2012).

In some songbird species, such as zebra finches (Taeniopygia guttata), males are the exclusive vocal learners (Immelmann, 1969). Males learn song during two devel-

Received September 12, 2017; accepted October 26, 2017; First published November 30, 2017.

The authors declare no competing financial interests.

Author contributions: D.M.V. and L.R.-H. designed the research; D.M.V. performed the research; D.M.V., M.M.-L., and L.R.H. analyzed the data; D.M.V., M.M.-L., and L.R.-H. wrote the paper.

NIH (R01NS082179); NSF (IOS1354906); University of Massachusetts Amherst Graduate School Dissertation Grant.

Acknowledgments: We thank Olivia Li, Garrett Scarpa, Maaya Ikeda, Amanda Krentzel, Christina Moschetto, Jessica Neves, Miranda Senft, and Amelia Ho for technical and animal care assistance with this project; and Jon Sakata for providing audio recordings of Bengalese finch song.

Correspondence should be addressed to Luke Remage-Healey, Center for Neuroendocrine Studies, University of Massachusetts, Amherst MA 01003. E-mail: healey@umass.edu.

DOl:http://dx.doi.org/10.1523/ENEURO.0317-17.2017

Copyright () 2017 Vahaba et al.

This is an open-access article distributed under the terms of the Creative Commons Attribution 4.0 International license, which permits unrestricted use, distribution and reproduction in any medium provided that the original work is properly attributed. opmental phases (Fig. 1A). In the sensory phase, birds acquire an auditory memory of their tutor's song, and then slowly refine their burgeoning vocalizations to approximate this tutor memory during the sensorimotor phase (Mooney, 2009). Research on the neural circuitry of vocal learning has largely explored song production premotor and cortico-basal ganglia circuits (Roberts et al., 2012; Brainard and Doupe, 2013). While auditory processing is necessary for song learning (Thorpe, 1954; Konishi, 1965), far less is known about the contribution of the auditory cortex during song learning in early development.

The caudomedial nidopallium (NCM; Fig. 1B) is key for auditory processing. NCM receives projections from primary cortical thalmo-recipient Field L, and is considered the avian analog of the mammalian secondary auditory cortex (Vates et al., 1996; Wang et al., 2010). NCM is important for both processing species-specific vocal communication (Mello et al., 1992; Theunissen et al., 2004) and auditory memory consolidation (Chew et al., 1995; London and Clayton, 2008; but see Canopoli et al., 2014). Further, much like the neural circuits for human language processing, NCM's role in auditory memory encoding and processing appears to be lateralized (Avey et al., 2005; Moorman et al., 2012, 2015; De Groof et al., 2013). Despite this clear role in auditory function, it is unclear how NCM's response properties shift across the vocal learning critical period.

In zebra finches, auditory behavioral perception and discrimination are adult-like as early as $\sim 30$ days posthatching (dph; Braaten et al., 2006). Studies on developmental changes in NCM neurophysiology have focused on the putative opening and closing of the sensory phase (20 and 30-35 dph, respectively; Böhner, 1990), but not beyond (Stripling et al., 2001; Miller-Sims and Bottjer, 2014). While there are subtle differences between juvenile age groups for song selectivity, auditory preferences and response magnitude at $35 \mathrm{dph}$ are comparable to adults. Similarly, Jin and Clayton (1997) found that NCM neuronal cell density is also similar to adults at 20 and $30 \mathrm{dph}$. To date, changes in communication processing in auditory 
A

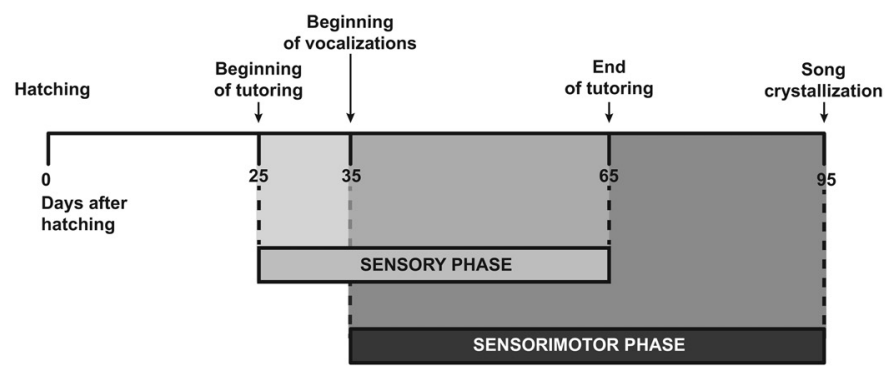

C
B

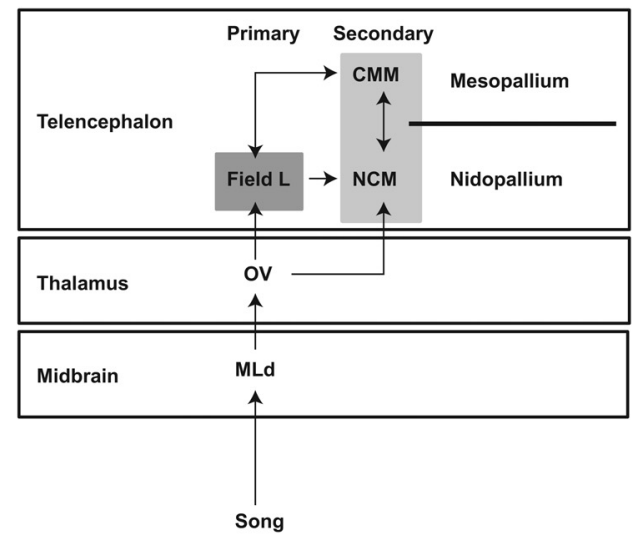

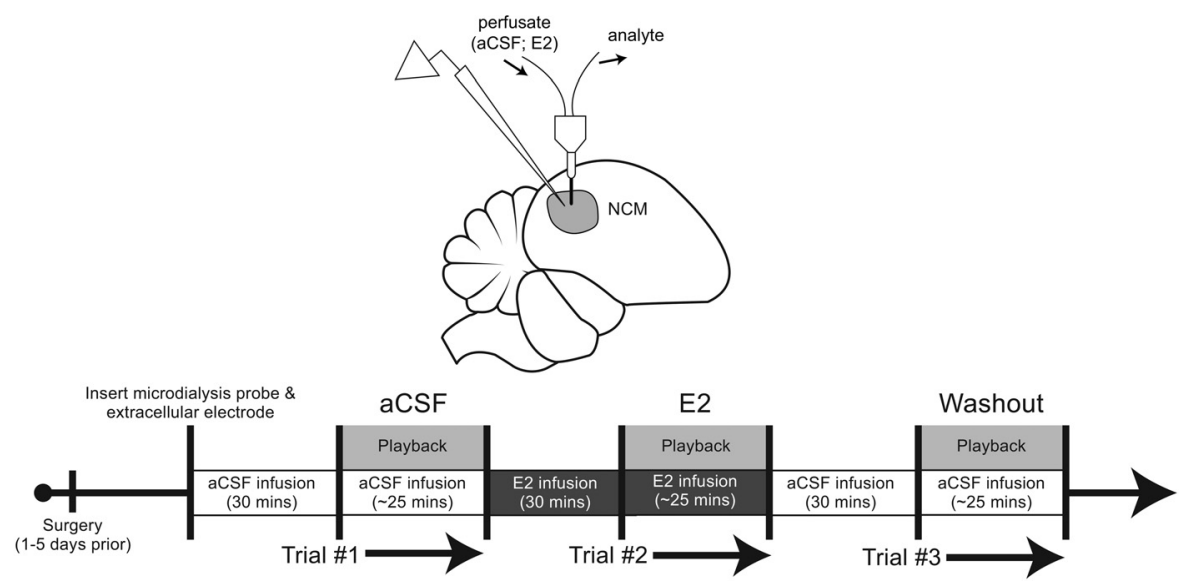

Figure 1. Critical period timeline, avian auditory circuit, and experimental paradigm. $\boldsymbol{A}$, The critical period for song learning unfolds across a 3 month timespan. Whereas some songbird species begin song learning and recognition at embryonic stages of development (Colombelli-Négrel et al., 2012), zebra finch sensory learning begins at 25 dph (Clayton, 2013). Autogenous song production can occur as early as $35 \mathrm{dph}$ (typically closer to $40 \mathrm{dph}$; personal observation), and initially overlaps with the sensory learning phase, until $65 \mathrm{dph}$ when sensorimotor-only learning continues as birds begin to refine their developing subsong until eventual song crystallization ( $\sim 100 \mathrm{dph})$. Timeline adapted after Clayton (2013). B. Schematic of the avian ascending auditory neural circuit. After sounds are first processed in upstream peripheral and brainstem auditory regions, communication is encoded within the midbrain nucleus MLd (dorsal part of the lateral mesencephalic nucleus), which sends projections to the thalamic nucleus ovoidalis (Ov). Ov sends projections primarily to Field L, comparable to mammalian primary auditory cortex, as well as to NCM (Vates et al., 1996). Secondary auditory cortex regions NCM (caudomedial nidopallium) and CMM (caudomedial mesopallium) are reciprocally connected and receive afferent projections from Field $\mathrm{L}$. C, Experimental setup and paradigm. Top: In vivo microdialysis and extracellular electrophysiology schematic. A microdialysis cannula was first descended into NCM ( 1.10 mm ventral; light gray circular region). Afterward, a carbon-fiber electrode was placed within the proximate region of perfusate diffusion. Bottom: Experimental timeline. aCSF, artificial cerebrospinal fluid; $\mathrm{E}_{2}$, $17 \beta$-estradiol.

forebrain outside of the sensory phase has been limited to immediate-early gene studies on 45-dph zebra finches (Bailey and Wade, 2003, 2005) and physiology studies on tutor song selectivity at $\sim 22$ or $\sim 60 \mathrm{dph}$ (Adret et al., 2012; Yanagihara and Yazaki-Sugiyama, 2016, respectively).

Circulating estrogens fluctuate across the critical period in several songbird species (Pröve, 1983; Weichel et al., 1986; Marler et al., 1988; but see Adkins-Regan et al., 1990) and predict vocal learning success (Marler et al., 1987), as in humans (Wermke et al., 2014). Estradiol levels in NCM gradually increase over the critical period, and also acutely in response to single tutoring bouts in juvenile male zebra finches (Chao et al., 2015). In adult songbirds, both circulating (references) and brain-derived estrogens (neuroestrogens; namely $17 \beta$-estradiol $\left[\mathrm{E}_{2}\right]$; Remage-Healey et al., 2010; Remage-Healey and Joshi, 2012) generally enhance complex communication encoding within telencephalic auditory brain regions, including NCM. Unlike other avian auditory forebrain nuclei that are devoid of estrogen synthase
(Field L and CMM; Fig. 1B), NCM is highly enriched with aromatase (Saldanha et al., 2000; Peterson et al., 2005). Moreover, while ascending auditory circuits are conserved across Aves, aromatase is uniquely found within the NCM of vocal learners (Metzdorf et al., 1999; Silverin et al., 2000). Together, these observations suggest that fluctuating neuroestrogens in NCM may dynamically influence auditory processing in development.

We tested two hypotheses, that (1) auditory responsiveness to natural communication signals in NCM changes across the critical period for vocal learning; and (2) NCM auditory responsiveness and coding are rapidly modulated by changes in local estrogens.

\section{Materials and Methods}

\section{Subjects}

All animal procedures were performed in accordance with the Institutional Animal Care and Use Committee at the University of Massachusetts Amherst. Male zebra 
finches ( $N=31$ birds; $n=26$ for estradiol experiments; $n=$ 5 for control recordings) were obtained from our breeding colonies, ranging in age from 25 to $95 \mathrm{dph}$. Hemisphere was considered the unit of replication, as NCM is a bilateral structure with no direct reciprocal connections between hemispheres (Vates et al., 1996). Subjects were initially binned by age reflecting the different critical period phases for song learning (Fig. 1A): sensory, 25-34 dph (left $=4$; right $=5$ ); sensory/sensorimotor: 40-64 dph (left = 13; right $=8$ ); and sensorimotor: 65-95 dph (left = 5 ; right $=3$ ). Zebra finches begin displaying overt sexually dimorphic plumage at $\sim 40 \mathrm{dph}$. For subjects $<40 \mathrm{dph}$ or that did not have male features (black striations, brown badge feathers, orange cheeks, etc.), DNA was extracted from whole blood, and PCR was run to determine sex (see below). Subjects were raised in mixed-sex breeding colonies in a 14:10 light:dark cycle. Once selected for the experiment, subjects were housed in an acoustic isolation chamber with a nonrelated adult companion female. For presinging 25- to 34-dph subjects, either the experiment was conducted the same day as the surgery, or subjects were isolated with a companion female for $1 \mathrm{~d}$ before the experiment. For 40- to 95-dph birds, subjects were cohoused with a companion female for 2-7 days before the experiment to capture birds' own song (BOS), which was recorded using Sound Analysis Pro (Tchernichovski et al., 2000) via an omnidirectional microphone (Countryman) inside a sound-attenuation chamber (Eckel Acoustics).

\section{Sex determination PCR}

For juvenile birds without discernable male features ( $<35 \mathrm{dph}$ ), whole blood was obtained from the ulnar vein, and DNA was subsequently extracted using a commercially available kit (QIAmp DNA Mini Kit; Qiagen \#51304). Purified DNA was subsequently used for PCR using a set of degenerate primers linked to the Z- and W-chromosomes (Griffiths et al., 1998). Amplified PCR product was then visualized alongside a negative control (water) and both adult male and female positive controls on a $2 \%$ agarose gel using electrophoresis. Subjects with two bands separated by $36 \mathrm{bp}$ were excluded from the study (indicating presence of W chromosome; thus females), and subjects showing a single band (indicating no W chromosome) were retained for the experiment.

\section{Surgery}

Surgery was performed 1-5 d before the experiment for most subjects (Fig. 1C; surgery was conducted the day of recordings in 2 birds). Animals were food deprived for 30 min before an intramuscular injection of Equithesin (30-40 $\mu \mathrm{L})$, and 20 min later, birds were wrapped in a cloth jacket and secured to a custom designed surgical stereotaxic apparatus ( $45^{\circ}$ head angle; Herb Adams Engineering) with a heating pad underneath $\left(36^{\circ} \mathrm{C}\right)$. Scalp feathers were removed, and a $20 \mu \mathrm{L}$ subcutaneous injection of lidocaine ( $2 \%$ in ethanol; Sigma-Aldrich) was administered under the scalp. The scalp was then resected, and a positioning-needle was placed just posterior to the midsagittal sinus bifurcation (MSB) and used as a 0-point anatomic reference. The skull was then marked at the anterior-most extent of NCM: rostral $=-1.20 \mathrm{~mm}$ and lateral $/$ medial $=0.90 \mathrm{~mm}$, relative to the MSB. This marking provided a site for microdialysis probe implantation on the day of recording (see below) alongside recording electrodes immediately adjacent (caudal) into NCM. A silver wire was implanted between skull leaflets over the cerebellum to serve as a reference ground. A head-post was then affixed to the bird using cyanoacrylate and dental cement. After surgery, birds were placed in a recovery cage on a heating pad $\left(36^{\circ} \mathrm{C}\right)$ with available food and water until they awoke from the anesthetic. After recovery, birds were given an oral administration of Meloxicam (1 $\mu \mathrm{L} / \mathrm{g}$ weight; $0.1 \mathrm{mg} / \mathrm{mL}$ ) and returned to their acoustic isolation chamber in a separate cage from the companion female.

\section{Anesthetized extracellular electrophysiology and acute estradiol treatment}

On the day of the experiment, subjects were food deprived for 30 min before initial anesthetic injections. After 30 min of food deprivation, $90-100 \mu \mathrm{L}$ of $20 \%$ urethane was evenly administered across three injections separated by 45 min each. Once the subject was anesthetized, subjects were brought to the recording room and affixed to a custom head-post stereotaxic apparatus $\left(45^{\circ}\right.$ head angle; Herb Adam Engineering). A small fenestra was made over one hemisphere of NCM and the dura was resected. A microdialysis probe (CMA-7; Harvard Apparatus) was first inserted just anterior to the intersecting point of NCM (as marked by the prior surgery; $\sim 1.10 \mathrm{~mm}$ ventral; Fig. 1C), and artificial cerebrospinal fluid (aCSF) was perfused at 2 $\mu \mathrm{l} / \mathrm{min}$ using a syringe pump (PHD 2000; Harvard Apparatus). Implanting microdialysis probes creates an acute injury in the brain, which induces a local increase in glial aromatase after $24 \mathrm{~h}$ in male zebra finches (Saldanha et al., 2013). Here, microdialysis probes were implanted for no longer than $4 \mathrm{~h}$, so it is unlikely that injury-induced glial aromatase influenced NCM properties within the time course of the current experiments.

After the probe was inserted, a carbon fiber electrode (CarboStar-1; Kation) was placed within the proximity of the microdialysis probe, and a recording site was found using search stimuli (Fig. 1C). A recording site was determined as being within NCM based on its: (1) anatomic coordinates (0.80-1.40 mm ventral) and (2) spontaneous and stimulus-evoked activity using a set of nonexperimental stimuli (search stimuli; see below).

After at least 30 min of aCSF infusion had elapsed, the first of three trials began (Fig. 1C). Each trial included 20 repeats of each stimulus with an interstimulus interval of $10 \pm 2$ s (experimental stimuli; see below), lasting $\sim 25$ min. After the end of the first playback trial, $17 \beta$-estradiol $\left(\mathrm{E}_{2} ; 30 \mu \mathrm{g} / \mathrm{mL}\right.$ [110 $\left.\mu \mathrm{M}\right]$; dose based on similar studies; Remage-Healey et al., 2010, 2012; Remage-Healey and Joshi, 2012; Pawlisch and Remage-Healey, 2015) was retrodialyzed for $30 \mathrm{~min}$, and afterward, a new playback period (using the same stimuli as in trial 1) was presented while $E_{2}$ was continuously infused. The same steps for $E_{2}$ were repeated with aCSF alone for trial 3 as a washout period. At the end of the recording session, electrolytic lesions were performed at the recording site for later anatomic confirmation. The infusion/playback regimen in 
trials 1-3 was repeated when possible in the contralateral $\operatorname{NCM}(n=12$ of 26 subjects).

At the end of the experiment, birds were killed via rapid decapitation. Brains were removed and placed in a $20 \%$ sucrose-formalin solution at $4^{\circ} \mathrm{C}$ to allow for tissue fixation. Once fixed, brains were frozen in an embedding medium (O.C.T. compound; Tissue-Plus; Fisher HealthCare) and stored at $-80^{\circ} \mathrm{C}$ until being sectioned at $45 \mu \mathrm{m}$ and Nissl-stained for histologic verification of probe and electrode placement.

\section{Auditory stimuli and playback}

Five unique conspecific songs and one white noise (WN) stimulus were used to initially identify auditory responsive recording sites typical of NCM (search stimuli). For playback trials, a unique set of experimental stimuli were used and included two novel conspecific male songs (CON1 and CON2; different from search stimuli CON), heterospecific song (Bengalese finch; HET), and WN. Bird's own song (BOS) and temporally reversed BOS (REV-BOS) was used when available for 40- to 95-dph animals. If BOS was unavailable for a 40- to 95-dph subject $(n=4)$, an age-matched juvenile male conspecific song (JUV CON) and temporally reversed JUV CON (REV-JUV CON) was used instead. For all sensory-aged subjects, a 40-dph JUV CON and REV-JUV CON was presented in place of BOS and REV-BOS. All stimuli were $\sim 2 s$ in duration (two motif renditions of directed song with introductory notes; $\sim 1.7$ - to 2.4-s total duration), normalized to $\sim 70 \mathrm{~dB}$ (A-weighted) and bandpass filtered at $0.3-15 \mathrm{kHz}$ using Adobe Audition. Each playback trial randomly presented 20 repetitions of each stimulus ( 15 repetitions initially for the first 3 subjects) with a randomly determined interstimulus interval of $10 \pm 2 \mathrm{~s}$ between each stimulus. The average playback trial duration was $\sim 25 \mathrm{~min}$.

\section{Data analysis}

Multiunit electrophysiological recordings were analyzed offline using Spike2 (v.7.04, Cambridge Electronic Design). For each unique subject's multiunit analysis, a voltage threshold to distinguish signal from noise was initially set based on Trial 1 and was maintained across all subsequent trials. Thresholds were set at least 2-fold above the noise-band of a given recording. Recordings were then analyzed by suprathreshold activity aligned to the playback of auditory stimuli. Stimulus-evoked firing frequency was defined as the total number of spikes (threshold crossings) $2 \mathrm{~s}$ after auditory stimulus onset divided by the number of trials (stimulus repeats), whereas spontaneous firing frequency was defined as the number of threshold crossings 2-s period before the onset of an auditory stimulus divided by the total number of trials. To account for firing variability across subjects, auditory responses were normalized using $z$-score transformations using the following equation:

$$
z \text {-score }=\frac{\bar{S}-\bar{B}}{\sqrt{\operatorname{Var}(S)+\operatorname{Var}(B)-2 \operatorname{Covar}(S, B)}},
$$

where $S$ is the number of spikes during stimulus response $(2 \mathrm{~s}$, beginning at stimulus onset), and $B$ is the number of spikes during baseline (2 $\mathrm{s}$ before stimulus onset). $\bar{S}$ and $\bar{B}$ represent the means of these values across all stimulus presentations for a given playback trial.

\section{Single-unit spike sorting}

Although multiunit physiologic recordings provide information about population responses, we also isolated single neurons to investigate auditory responsiveness for cells with high signal-to-noise ratios. Isolating single units provides an increased sample size, reducing animal usage numbers and allowing us to track the response properties of single neurons (1-2 units per recording site) over time in response to estrogen modulation. To identify putative single neurons for analysis, Trial 1 multiunit recordings were sorted for large-amplitude single-unit templates based on wave form using default settings in Spike2 $(n=$ 53 single units). Sorted single units were retained for analysis if they were distinctly clustered from noise or other units in a principal components analysis space and had an interspike interval (ISI) $>1 \mathrm{~ms}$ (i.e., zero ISls were within the 1-ms bin for all units; Fig. $3 A$ ). After sorting, each single unit was confirmed to be auditory responsive using visual inspection of peristimulus time histograms, as well as by paired $t$ tests comparing each unit's spontaneous and stimulus-evoked firing rates. Units that were statistically responsive $(p<0.05)$ to at least one auditory stimulus during Trial 1 were included. On average, each multiunit recording site yielded 1-2 distinct and auditoryresponsive single units. Peak-to-trough wave form durations were measured to initially distinguish broad- versus narrow-spiking neurons (as in Schneider and Woolley, 2013; Yanagihara and Yazaki-Sugiyama, 2016); however, we did not observe cell type-specific descriptive effects. Also because of inferential statistical power limitations, we opted to group all single units in our analyses and disregard wave form classifications.

\section{Pattern classifier}

A custom pattern classifier was developed in Python to assess reliability and discriminability of neuronal responses to different stimuli (similar to Caras et al., 2015; as in Lee et al., 2017). For each single-unit recording, the stimulusevoked firing responses to the 6 different stimuli were compared iteratively. At the start of each run of the classifier, one trial of each stimulus was pseudorandomly selected as the template (6 templates). All remaining 19 trials for each stimulus (114 trials total) were compared one at a time to the templates using a similarity measure. This procedure was repeated 1000 times to generate a confusion matrix, which represents data in terms of actual versus predicted stimulus classification (Fig. 3F).

Before comparison, each response to a stimulus iteration was Gaussian filtered. The standard deviation $(\sigma)$ of the filter was employed as a variable for each cell, i.e., the classifier was run with varying $\sigma$ values of $1,2,4,8,16,32$, 64,128 , and $256 \mathrm{~ms}$ (1000 simulations for each). The filter that yielded the highest accuracy score was used for that cell. Templates and trials were correlated by using the $R_{\text {corr }}$ method (Schreiber et al., 2003; Caras et al., 2015): 


$$
R_{\text {corr }}=\frac{\vec{s}_{\text {trial }} \cdot \vec{s}_{\text {template }}}{\left|\vec{s}_{\text {trial }}\right| \cdot\left|\vec{s}_{\text {template }}\right|},
$$

where $\vec{s}$ represents the vectors of the trial and the template responses after filtering, which are dot-multiplied then divided by the product of their lengths. This calculation returns a value between 0 and 1 , which represent total dissimilarity or total similarity, respectively. The stimulus type of the template that provided the highest $\mathrm{R}_{\text {corr }}$ (trial, template) value was considered the predicted stimulus for the trial in analysis. Therefore, percentage accuracy scores were generated by how well each neuron's firing pattern was predictive of the auditory stimulus.

The classifier output for each neuron was assessed statistically via a trial shuffling approach (Caras et al., 2015). Trials were stripped of stimulus labels, pseudorandomly shuffled and relabeled, essentially generating random responses to the stimuli. The pattern classifier was then run with this shuffled dataset. The distribution of the accuracies (means of diagonals in the confusion matrices) generated in each run of the original dataset was compared with the shuffled dataset via Cohen's $d$. Cohen's $d$ was $>0.2$ for all single units included in our analysis, which is considered a modest effect size (Cohen, 1988). As there were 6 stimuli presented to each bird, the trial shuffling accuracy yields distributions centered at $16.67 \%$ (i.e., "chance" graphed for visual reference; e.g., dashedline in Fig. 3F). In contrast to the z-score, which measures how much the stimulus response is relative to baseline across all trials, $R_{\text {corr }}$ is a correlation-based metric that takes into account spike-timing variability phenomena such as jitter, missing spikes, and noise in a trial-by-trial basis (Schreiber et al., 2003).

\section{Code accessibility}

The Python code developed for the pattern classifier can be made available on request.

\section{Statistical analyses}

All statistical analyses were performed using IBM SPSS Statistics for Windows (v.23). To test for developmental shifts in multiunit activity, we conducted three-way ANOVAs (phase $\times$ hemisphere $\times$ stimulus) separately on Trial 1 data (aCSF: $z$-score, firing rates, and classification accuracy). Similar methods were used for testing development changes in single-unit activity. To determine effects of $E_{2}$ on auditory responsiveness, we performed a mixed-effects ANOVA (ME-ANOVA; within-subject factor: treatment; between-subject factors: hemisphere, stimuIus). Separate ME-ANOVAs were run for $<35$-dph versus $\geq 40$-dph subject (see Results). For ME-ANOVAs, we restricted our statistical analyses to aCSF and $E_{2}$ trials (1 and 2 , respectively), as we were interested in estrogenic effects on auditory processing; however, we present washout data (Trial 3) in all relevant figures to provide a visual comparison. If a significant interaction was found in the MEANOVA model (e.g., significant hemisphere $\times$ trial interaction), separate follow-up ME analyses were run for each factor level (e.g., separate analysis for left versus right $\mathrm{NCM} \times$ trial). All post hoc comparisons were performed using Tukey's honestly significant difference (HSD) test. All statistical tests with $p<0.05$ were considered significant. See Table 1 for all statistical tests employed for each figure illustrated.

\section{Results}

\section{Distribution of ages by hemisphere}

We recorded from 26 unique juvenile male subjects. Of the initial 26 subjects, we obtained 12 successful bilateral recordings. NCM is a bilateral structure with no direct reciprocal connections between hemispheres (Vates et al., 1996), so drug infusions administered to the initial hemisphere are unlikely to directly impact physiology in the contralateral hemisphere. NCM recordings from adult males ( $\geq 195 \mathrm{dph}$ ) were obtained from a separate set of experiments using identical methods without microdialysis probe ( $n=4$ subjects) to serve as a visual comparison (e.g., Fig. 2B).

\section{Developmental shifts in NCM auditory physiology and encoding}

As we were interested in developmental differences in auditory responses, we initially divided our data into three conventional age groups based on their phase in the critical period for song learning (Fig. 1A): (1) 25-34 dph (sensory-aged; $n=5$ ); (2) 40-64 dph (sensory/sensorimotor-aged; $n=13$ ); and (3) 65-95 dph (sensorimotoraged; $n=8$ ); as in Livingston and Mooney (2001).

We first analyzed multiunit recordings to assess whether auditory encoding during baseline conditions (Trial \#1; aCSF) differed across subjects depending on the developmental phase and hemisphere (Fig. 2A). Multiunit auditory z-scores in the left NCM were significantly higher than in the right NCM across development (left: $0.368 \pm 0.019$; right: $0.340 \pm 0.029$; mean $\pm \mathrm{SEM}, F_{(1,220)}=6.663, p=$ $0.010, \eta^{2}=0.035$ ). Further, there was a significant agedependent effect on auditory responsiveness (Fig. 2B; $\left.F_{(2,220)}=37.156, p<0.001, \eta^{2}=0.275\right)$, such that 25-34 dph phase subjects demonstrated significantly higher auditory $z$-scores $(0.563 \pm 0.037)$ compared with both 40-64 dph $(0.271 \pm 0.018 ; p<0.001)$ and $65-95 \mathrm{dph}$ subjects $(0.349 \pm 0.027 ; p<0.001)$; there were no significant differences between 40-64 dph and 65-95 dph subjects $(p=0.059)$. There were no significant hemisphere $*$ age interactions for Trial \#1 $z$-scores, $F_{(2,220)}=$ $1.464, p=0.233, \eta^{2}=0.012$. Further, multiunit classification accuracy showed a similar effect of age $\left(F_{(2,240)}=6.257\right.$, $\left.p=0.002, \eta^{2}=0.059\right)$, whereby 25-34 dph subjects had higher accuracies $(72.31 \pm 2.64 \%)$ compared with both 40-64 dph (54.20 $\pm 2.86 \% ; p<0.001)$ and $65-95 \mathrm{dph}$ $(58.46 \pm 4.05 \% ; p=0.001)$ subjects; $40-64$ and $65-95$ subjects were statistically similar $(p=0.936)$. No effect of hemisphere on accuracy was observed $\left(F_{(1,240)}=3.254\right.$, $p=0.073, \eta^{2}=0.016$ ).

As there were no overall age $\times$ hemisphere interactions for Trial 1 normalized auditory responses and classification accuracy, and because 40-64 dph and 65-95 dph subjects were statistically similar, we divided subjects into two juvenile age groups for all subsequent analyses: (1) sensory-aged (25-34 dph), and (2) sensorimotor-aged (40-95 dph). This division closely matches a major devel- 
Table 1. Statistical table

\begin{tabular}{|c|c|c|c|}
\hline Results & Data structure & Type of test & Observed power $(\alpha=0.05)$ \\
\hline Fig. $2 B, z$-score & $\begin{array}{l}\text { Assumed normal distribution; age } \\
\text { (25-34; 40-64; 65-95 dph) } \times \\
\text { hemisphere (left NCM; right NCM) }\end{array}$ & Three-way ANOVA & $\begin{array}{l}\text { Hemisphere }=0.728 \text {; age }=1.00 \\
\quad \text { hemisphere } \times \text { age }=0.251\end{array}$ \\
\hline $\begin{array}{l}\text { Fig. } 2 C \text {, spontaneous } \\
\text { firing rate }\end{array}$ & $\begin{array}{l}\text { Assumed normal distribution; phase (sensory; } \\
\text { sensorimotor) } \times \text { hemisphere (left NCM; right NCM) }\end{array}$ & Three-way ANOVA & $\begin{array}{l}\text { Hemisphere }=0.058 ; \text { phase }=0.738 \\
\quad \text { hemisphere } \times \text { phase }=0.266\end{array}$ \\
\hline $\begin{array}{l}\text { Fig. } 2 D \text {, stimulus-evoked } \\
\text { firing rate }\end{array}$ & $\begin{array}{l}\text { Assumed normal distribution; phase (sensory; } \\
\text { sensorimotor) } \times \text { hemisphere (left NCM; right NCM) }\end{array}$ & Three-way ANOVA & $\begin{array}{l}\text { Hemisphere }=0.092 ; \text { phase }=0.918 \\
\quad \text { hemisphere } \times \text { phase }=0.626\end{array}$ \\
\hline Fig. 3C, $z$-score & $\begin{array}{l}\text { Assumed normal distribution; phase (sensory; } \\
\text { sensorimotor) } \times \text { hemisphere (left NCM; right NCM) }\end{array}$ & Three-way ANOVA & $\begin{array}{l}\text { Hemisphere }=0.057 ; \text { phase }=0.999 \\
\quad \text { hemisphere } \times \text { phase }=0.105\end{array}$ \\
\hline $\begin{array}{l}\text { Fig. } 3 D \text {, classification } \\
\text { accuracy }\end{array}$ & $\begin{array}{l}\text { Assumed normal distribution; phase (sensory; } \\
\text { sensorimotor) } \times \text { hemisphere (left NCM; right NCM) }\end{array}$ & Three-way ANOVA & $\begin{array}{l}\text { Hemisphere }=0.051 ; \text { phase }=0.918 \\
\quad \text { hemisphere } \times \text { phase }=0.070\end{array}$ \\
\hline $\begin{array}{l}\text { Fig. } 3 E \text {, spontaneous } \\
\text { firing rate }\end{array}$ & $\begin{array}{l}\text { Assumed normal distribution; phase (sensory; } \\
\text { sensorimotor) } \times \text { hemisphere (left NCM; right NCM) }\end{array}$ & Three-way ANOVA & $\begin{array}{l}\text { Hemisphere }=0.482 ; \text { phase }=0.815 \\
\quad \text { hemisphere } \times \text { phase }=0.069\end{array}$ \\
\hline $\begin{array}{l}\text { Fig. } 3 F \text {, stimulus-evoked } \\
\text { firing rate }\end{array}$ & $\begin{array}{l}\text { Assumed normal distribution; phase (sensory; } \\
\text { sensorimotor) } \times \text { hemisphere (left NCM; right NCM) }\end{array}$ & Three-way ANOVA & $\begin{array}{l}\text { Hemisphere }=0.084 ; \text { phase }=0.171 \\
\quad \text { hemisphere } \times \text { phase }=0.078\end{array}$ \\
\hline Fig. $4 A$, $z$-score & $\begin{array}{l}\text { Assumed normal distribution; trial (aCSF; E2) } \times \\
\text { hemisphere (left NCM; right NCM) }\end{array}$ & Mixed-effects ANOVA & $\begin{array}{l}\text { Trial }=0.866 ; \text { hemisphere }=0.119 \\
\quad \text { trial } \times \text { hemisphere }=0.182\end{array}$ \\
\hline $\begin{array}{l}\text { Fig. } 4 A \text {, inset; } z \text {-score } \\
\text { (rundown) }\end{array}$ & $\begin{array}{l}\text { Assumed normal distribution; trial (trial \#1-aCSF; } \\
\text { trial \#2-aCSF) }\end{array}$ & Mixed-effects ANOVA & Trial $=0.445$ \\
\hline $\begin{array}{l}\text { Fig. } 4 B \text {, classification } \\
\text { accuracy }\end{array}$ & $\begin{array}{l}\text { Assumed normal distribution; trial (aCSF; E2) } \times \\
\text { hemisphere (left NCM; right NCM) }\end{array}$ & Mixed-effects ANOVA & $\begin{array}{l}\text { Trial }=0.866 ; \text { hemisphere }=0.450 \\
\quad \text { trial } \times \text { hemisphere }=0.369\end{array}$ \\
\hline $\begin{array}{l}\text { Fig. } 4 C \text {, spontaneous } \\
\text { firing rate }\end{array}$ & $\begin{array}{l}\text { Assumed normal distribution; trial (aCSF; E2) } \times \\
\text { hemisphere (left NCM; right NCM) }\end{array}$ & Mixed-effects ANOVA & $\begin{array}{l}\text { Trial }=0.997 ; \text { hemisphere }=0.050 \\
\quad \text { trial } \times \text { hemisphere }=0.104\end{array}$ \\
\hline $\begin{array}{l}\text { Fig. } 4 D \text {, stimulus-evoked } \\
\text { firing rate }\end{array}$ & $\begin{array}{l}\text { Assumed normal distribution; trial (aCSF; E2) } \times \\
\text { hemisphere (left NCM; right NCM) }\end{array}$ & Mixed-effects ANOVA & $\begin{array}{l}\text { Trial }=0.960 ; \text { hemisphere }=0.185 \\
\quad \text { trial } \times \text { hemisphere }=0.363\end{array}$ \\
\hline Fig. $5 A$, z-score & $\begin{array}{l}\text { Assumed normal distribution; trial (aCSF; E2)- } \\
\text { separate analyses by hemisphere (left vs. right) }\end{array}$ & $\begin{array}{l}\text { Two-way repeated-measures } \\
\text { ANOVA }\end{array}$ & Left $\mathrm{NCM}=0.588 ;$ right $\mathrm{NCM}=0.303$ \\
\hline $\begin{array}{l}\text { Fig. } 5 B \text {, classification } \\
\text { accuracy }\end{array}$ & $\begin{array}{l}\text { Assumed normal distribution; trial (aCSF; E2)- } \\
\text { separate analyses by hemisphere (left vs. right) }\end{array}$ & $\begin{array}{l}\text { Two-way repeated-measures } \\
\text { ANOVA }\end{array}$ & Left $\mathrm{NCM}=0.293 ;$ right $\mathrm{NCM}=0.196$ \\
\hline $\begin{array}{l}\text { Fig. } 5 C \text {, spontaneous } \\
\text { firing rate }\end{array}$ & $\begin{array}{l}\text { Assumed normal distribution; trial (aCSF; E2)- } \\
\text { separate analyses by hemisphere (left vs. right) }\end{array}$ & $\begin{array}{l}\text { Two-way repeated-measures } \\
\text { ANOVA }\end{array}$ & Left $\mathrm{NCM}=0.629 ;$ right $\mathrm{NCM}=0.725$ \\
\hline $\begin{array}{l}\text { Fig. } 5 D \text {, stimulus-evoked } \\
\text { firing rate }\end{array}$ & $\begin{array}{l}\text { Assumed normal distribution; trial (aCSF; E2)- } \\
\text { separate analyses by hemisphere (left vs. right) }\end{array}$ & $\begin{array}{l}\text { Two-way repeated-measures } \\
\text { ANOVA }\end{array}$ & Left $\mathrm{NCM}=0.804 ;$ right $\mathrm{NCM}=0.758$ \\
\hline
\end{tabular}

opmental transition for young male zebra finches, namely before (sensory phase) and after (sensorimotor phase) autogenous singing begins (Clayton, 2013).

Developmental differences in $z$-score can be the result of elevated stimulus-evoked firing rates, reduced spontaneous firing rates, or a combination of both. Therefore, we assessed whether differences in multiunit spontaneous or stimulus-evoked firing frequency in NCM explained elevated $z$-scores in sensory-aged subjects (Fig. 2C, D). Sensory-aged subjects had both significantly reduced spontaneous firing $(13.246 \pm 0.977 \mathrm{~Hz})$ and higher stimulus-evoked firing $(39.087 \pm 0.2 .646 \mathrm{~Hz})$ compared with sensorimotor-aged subjects (spontaneous: $17.432 \pm$ $0.653 \mathrm{~Hz}, F_{(2,222)}=11.136, p=0.001, \eta^{2}=0.037$; stimulus-evoked: $27.295 \pm 0.864 \mathrm{~Hz}, F_{(2,222)}=11.136$, $\left.p=0.001, \eta^{2}=0.067\right)$. The effect of age on spontaneous firing rates was independent of hemisphere (hemisphere: $F_{(1,222)}=1.064, p=0.303, \eta^{2}=0.005$; hemisphere $*$ age: $\left.F_{(1,222)}=0.509, p=0.477, \eta^{2}=0.001\right)$. Similarly, no hemisphere $*$ age interactions $\left(F_{(1,22)}=2.032, p=0.155\right.$, $\left.\eta^{2}=0.005\right)$ or overall effect of hemisphere $\left(F_{(1,222)}=3.092\right.$, $\left.p=0.080, \eta^{2}=0.017\right)$ were found for stimulus-evoked firing.

\section{Developmental shifts in single-unit activity}

While examining multiunit activity provides information about how population of neurons respond to auditory stimuli, we also analyzed isolated single neurons using wave form template matching (Fig. $3 A$, B; see Methods) to investigate whether developmental changes in auditory responsiveness could be explained by the activity of single neurons. Spontaneous firing rates were lower in sensory-aged subjects $(3.34 \pm 0.28 \mathrm{~Hz})$ compared with sensorimotor-aged subjects $\left(4.91 \pm 0.25 \mathrm{~Hz} ; F_{(1,292)}=\right.$ 8.204, $p=0.004, \eta^{2}=0.027$; Fig. $3 C$ ). No other significant interactions or main effects were found for spontaneous firing. Stimulus-evoked firing was statistically similar in sensory-aged and sensorimotor-aged juveniles $\left(p=0.315 ; \eta^{2}=0.003 ;\right.$ Fig. $\left.3 D\right)$, and there was no effect of hemisphere $\left(F_{(1,292)}=0.293, p=0.589, \eta^{2}=0.001\right)$ or hemisphere $*$ age interaction $\left(F_{(1,292)}=0.239, p=0.626\right.$, $\eta^{2}=0.001$ ). As with the multiunit findings, single units from sensorimotor-aged males had significantly lower $z$-scores $(0.310 \pm 0.012)$ compared with units from sensory-aged males $\left(0.461 \pm 0.026 ; F_{(1,292)}=25.561 p<\right.$ $0.001, \eta^{2}=0.080$; Fig. $3 E$ ). There was no effect of hemisphere $\left(F_{(1,292)}=0.065, p=0.798, \eta^{2}<0.001\right)$ or hemisphere $*$ age interaction $\left(F_{(1,292)}=0.469, p=0.494\right.$, $\left.\eta^{2}=0.002\right)$ for single-unit $z$-scores.

To evaluate whether developmental changes in communication processing affected auditory encoding, we analyzed the physiology data using a pattern classifier (see Methods). Irrespective of hemisphere, sensory-aged subjects demonstrated higher accuracy rates $(53.86 \pm 2.50 \%)$ compared with sensorimotor-aged subjects $(40.38 \pm 1.57 \%$; $F_{(1,262)}=11.321, p=0.001, \eta^{2}=0.041$; Fig. $\left.3 F\right)$. In summary, our findings indicate that auditory neurons in NCM track critical period phase transitions leading to higher auditory responsiveness and coding in sensoryaged, presinging birds. 
A Age (dph)

MUA

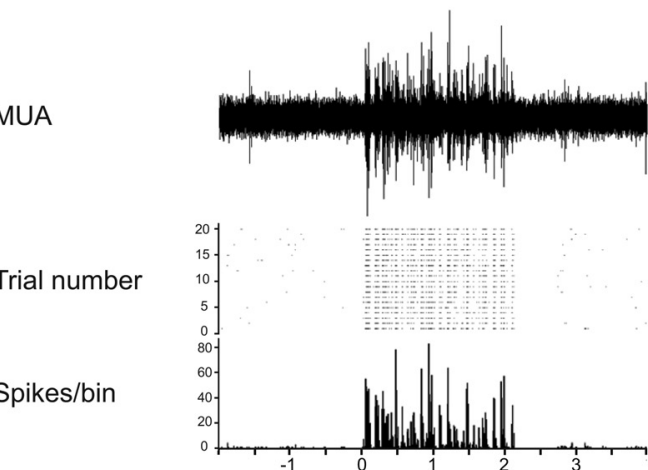

Song
$25-34$

$40-64$
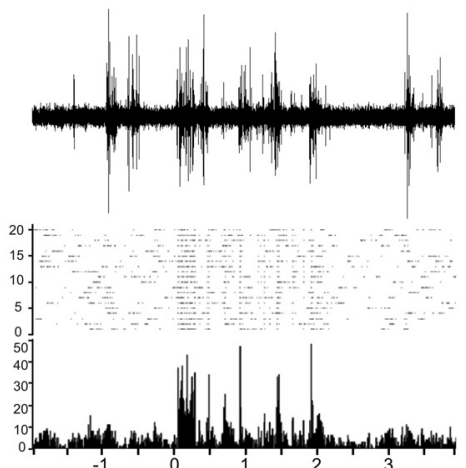

$65-95$
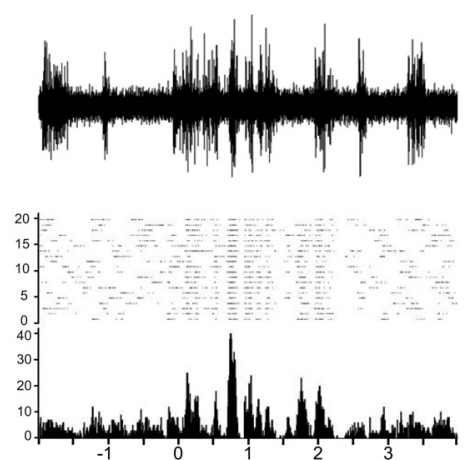

B

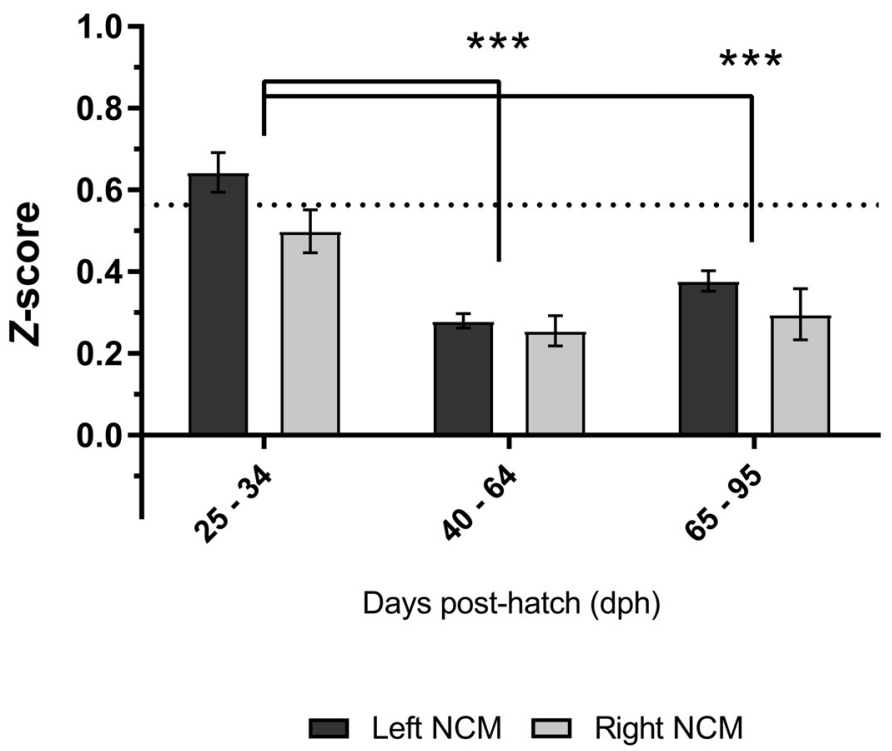

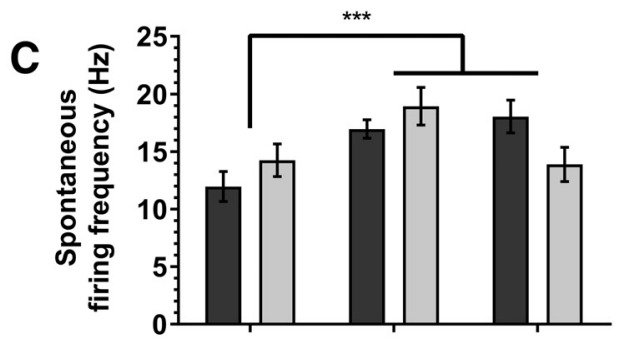

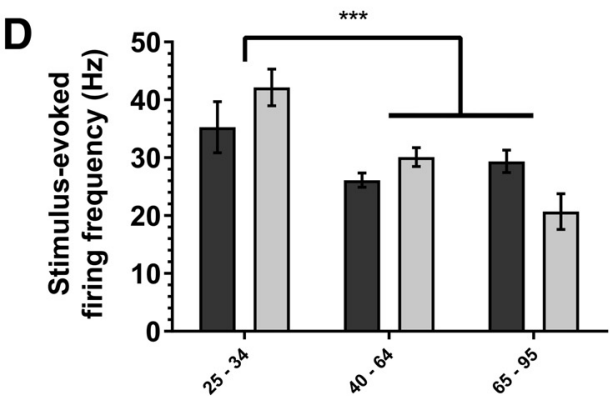

Days post-hatch (dph)

Figure 2. Multiunit shifts in NCM auditory responsiveness across development. $\boldsymbol{A}$, Representative multiunit recordings from a 25-, 47-, and 95-dph subject (right, left, and left hemisphere, respectively). Top: Representative response to a single presentation of conspecific song (CON2) from a multiunit recording during Trial 1 (aCSF). Middle: Raster plot and corresponding peristimulus time histogram (6-s duration) across all CON2 presentations during Trial 1 (aCSF). Bottom: CON2 sonogram. B, 25-34 dph subjects have higher normalized auditory response than both 40-64 and 65-95 dph birds. Dotted-line in $\boldsymbol{B}$ is average CON $z$-score from adult male NCM recordings from a separate study (graphed for visual comparison; $n=4$ birds [195-360 dph; average age $=267.7 \mathrm{dph}$ ]). $\boldsymbol{C}, \boldsymbol{D}$, Based on $z$-score results, we analyzed birds based on critical period phase (sensory [25-34 dph] vs. sensorimotor [40-95 dph]) and found that sensory-aged birds' NCM have lower spontaneous firing rates $(\boldsymbol{C})$ and elevated stimulus-evoked firing rates $(\boldsymbol{D})$ compared with sensorimotor-aged subjects. $* * * p<0.001$ (z-score: 25-34 dph vs. 40-64 dph, and 25-34 dph vs. 65-95 dph; spontaneous and stimulus-evoked firing: sensory-aged versus sensorimotor-aged). MUA, multiunit activity; CON2, conspecific song 2.

\section{Effects of estradiol on NCM physiology and encoding are hemisphere and age dependent}

Estradiol enhances stimulus-evoked activity in the NCM of adult male and female songbirds (Remage-Healey et al., 2010, 2012; Remage-Healey and Joshi, 2012). Further, $E_{2}$ production is rapidly enhanced in NCM during social interactions and song playbacks (Remage-Healey et al., 2008). While there are dynamic changes in neuroestrogen synthesis in the NCM of developing songbirds during and after song tutoring (Chao et al., 2015), it is unknown whether $\mathrm{E}_{2}$ locally modulates stimulus-evoked activity as in adults. Because we observed clear develop- 
A

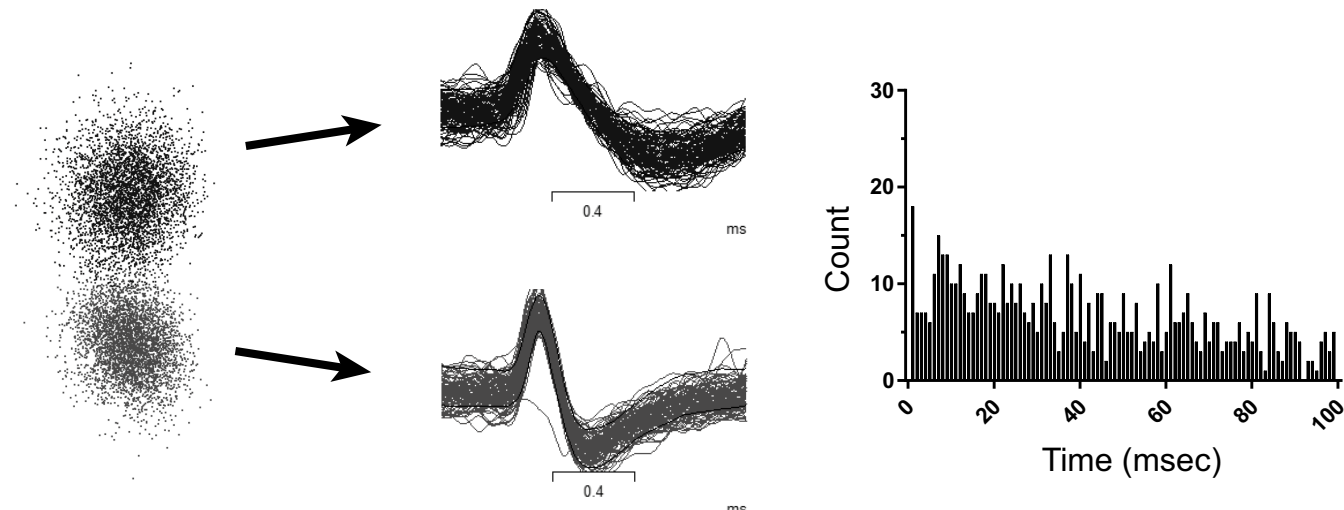

B
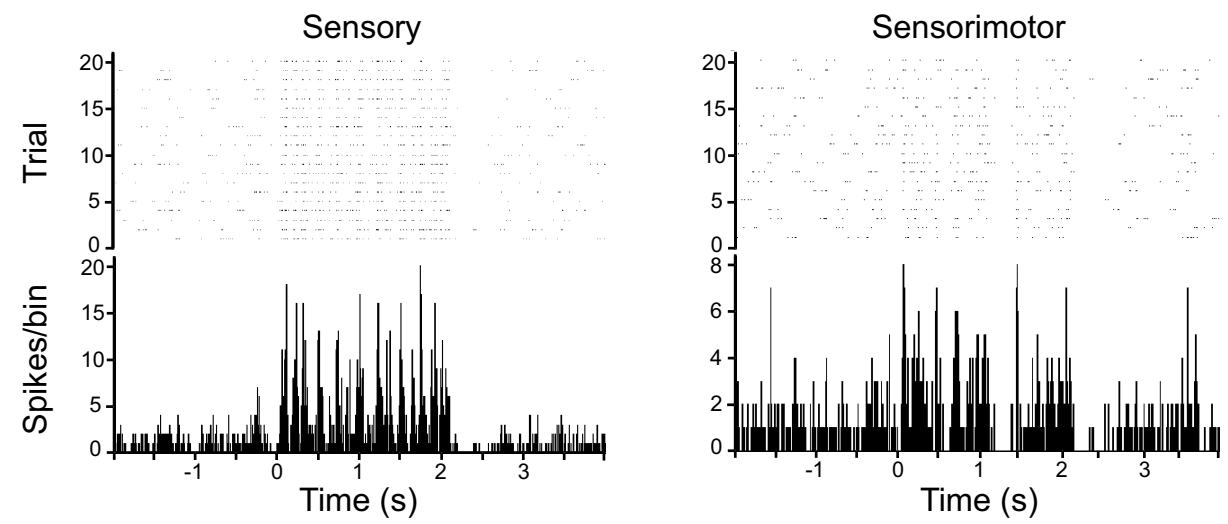

C

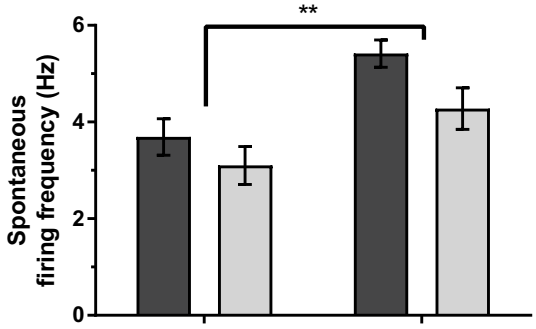

D

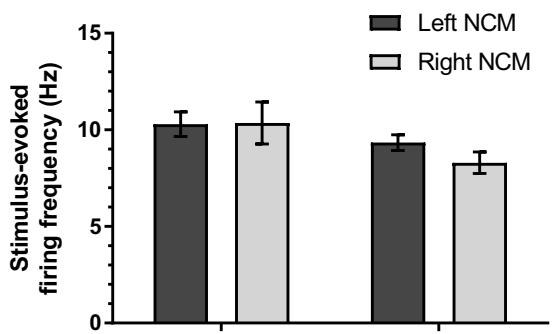

E

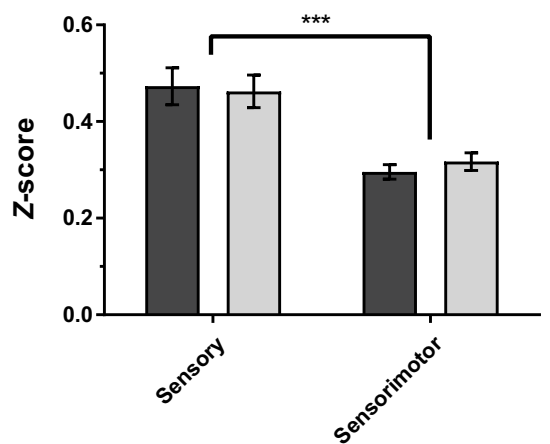

F
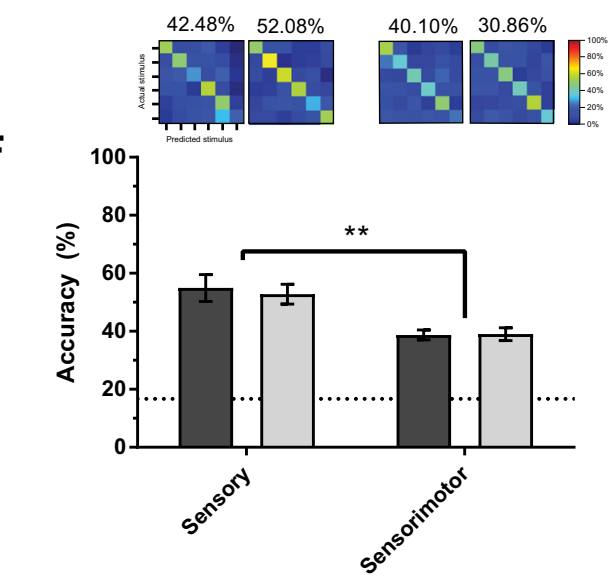

Figure 3. Single-unit auditory response and encoding in NCM is elevated during sensory phase. $A$, Representative single neurons. Left: Two sorted single units distinctly clustered in principal components space; Middle: 100 sequential iterations from two separate single 
continued

neurons overlaying their respective wave form template. Right: Interstimulus interval plots for top single unit. Each bin $=1 \mathrm{~ms}$. Units derived from Trial 1 (aCSF) recording from a sensory-aged subject (30 dph; left NCM). B, Raster plot and peristimulus time histogram from representative single units from a sensory-aged and sensorimotor-aged bird (33 [right NCM] and 71 [left NCM] dph). $\boldsymbol{C}, \boldsymbol{D}$, Spontaneous firing rates are lower in sensory-aged subjects irrespective of hemisphere; however, there are no age-dependent differences in single-unit stimulus-evoked firing rates $(\boldsymbol{D})$. $\boldsymbol{E}, \boldsymbol{F}$, Across hemispheres, single-unit auditory z-scores $(\boldsymbol{E})$ and classification accuracy $(\boldsymbol{F})$ are significantly higher in sensory-aged birds. Dotted-line in $\boldsymbol{F}$ is chance-level prediction for classifier ( 1 in 6 chance for accurately classifying a given stimulus $=16.67 \%$ ). $* * * p<0.001 ; * * p<0.01$ (sensory-aged vs. sensorimotor-aged)

mental differences in auditory responsiveness and coding, we elected to analyze subjects separately by age groups for $\mathrm{E}_{2}$ 's effect on auditory responsiveness.

\section{Estradiol reduces overall NCM firing in sensory-aged subjects}

Estradiol significantly decreased $z$-scores in sensory subjects (aCSF: $0.461 \pm 0.026 ; E_{2}: 0.406 \pm 0.035 ; F_{(1,72)}=$ 9.659, $p=0.003 ; \eta^{2}=0.118$; Fig. $4 A$ ), independent of hemisphere or stimulus $(p>0.292)$. As with normalized auditory responses, $E_{2}$ also reduced spontaneous and stimulus-evoked firing rates (spontaneous: $F_{(1,72)}=$ 23.085, $p<0.001 ; \eta^{2}=0.243$; stimulus-evoked: $F_{(1,72)}=$ 14.151, $p<0.001, \eta^{2}=0.164$; Fig. $4 C, D$ ), independent of hemisphere or hemisphere $*$ trial interactions $(p>0.05)$. Further, $E_{2}$ treatment reduced classification accuracy across both hemispheres; $F_{(1,54)}=7.68, p=0.003, \eta^{2}=$ 0.153 (aCSF: $51.18 \% \pm 3.35 ; E_{2}: 38.87 \% \pm 1.95$; Fig. $4 B$ ).

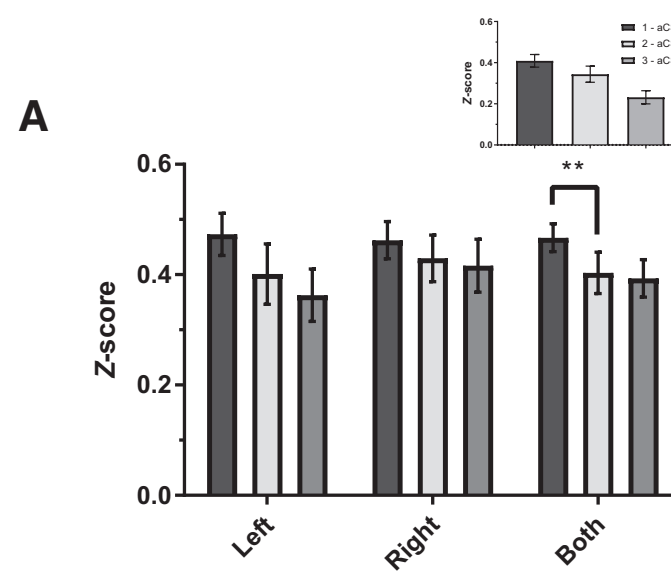

C

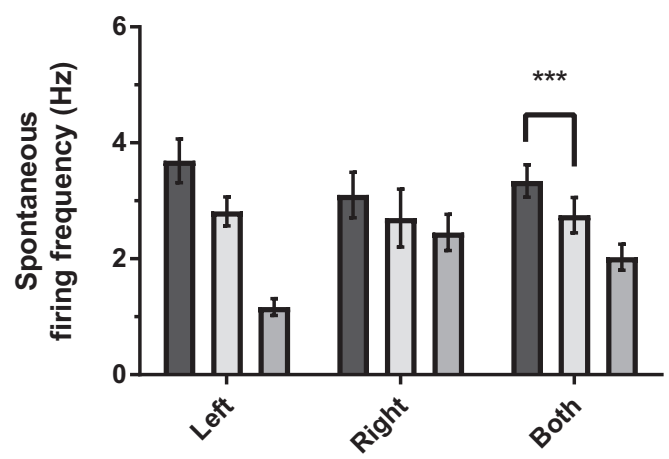

aCSF
B

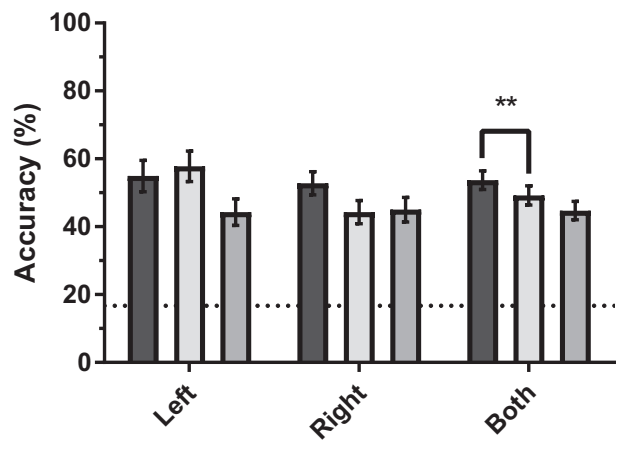

D

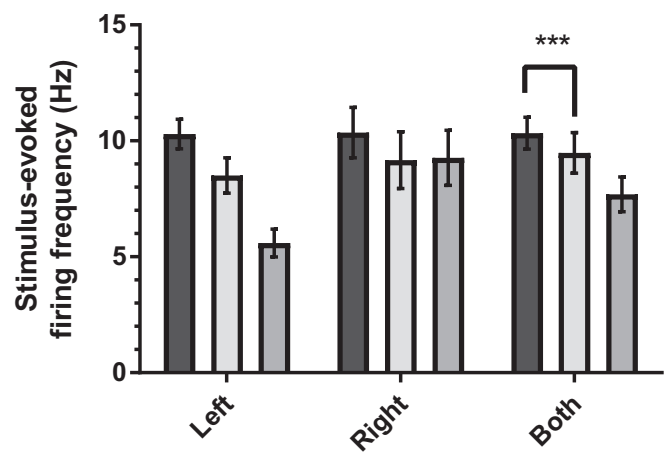

E2 Washout

Figure 4. Estradiol $\left(E_{2}\right)$ dampens auditory responsiveness in NCM. $\boldsymbol{A}-\boldsymbol{D}$, Relative to aCSF (Trial 1), $E_{2}$ treatment decreased $z$-scores $(\boldsymbol{A})$, classification accuracy $(\boldsymbol{B})$, and spontaneous $(\boldsymbol{C})$ and stimulus-evoked $(\boldsymbol{D})$ firing rates in the NCM of sensory-aged subjects. Hemisphere-specific averages are depicted for visual comparison and consistency, but there was no trial $\times$ hemisphere effect. Averaged measurements across hemispheres are depicted in the last set of columns (Both); $* * p<0.01$ (effect of trial; Trial 1 vs. Trial 2). Dotted-line in $B$ is chance-level prediction for classifier ( 1 in 6 chance for accurately classifying a given stimulus $=16.67 \%$ ). Inset in $\boldsymbol{A}$, average $z$-score across trials in aCSF rundown experiment $(p=0.07$; Trial 1 vs. Trial $2 ; n=5$ sensory-aged birds; 6 single units). 
A

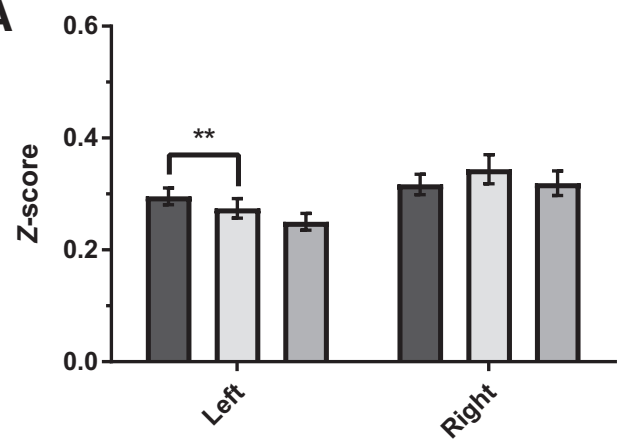

C

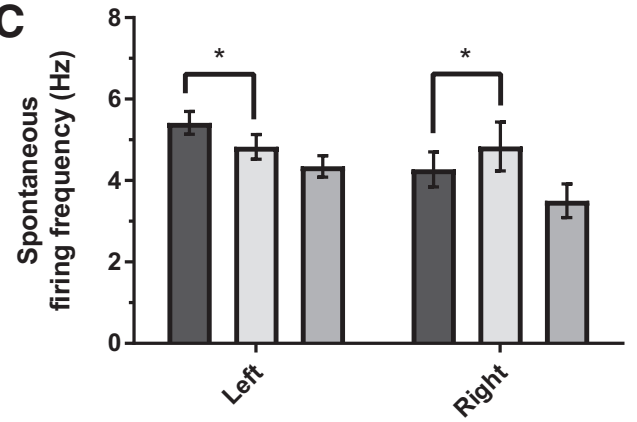

B
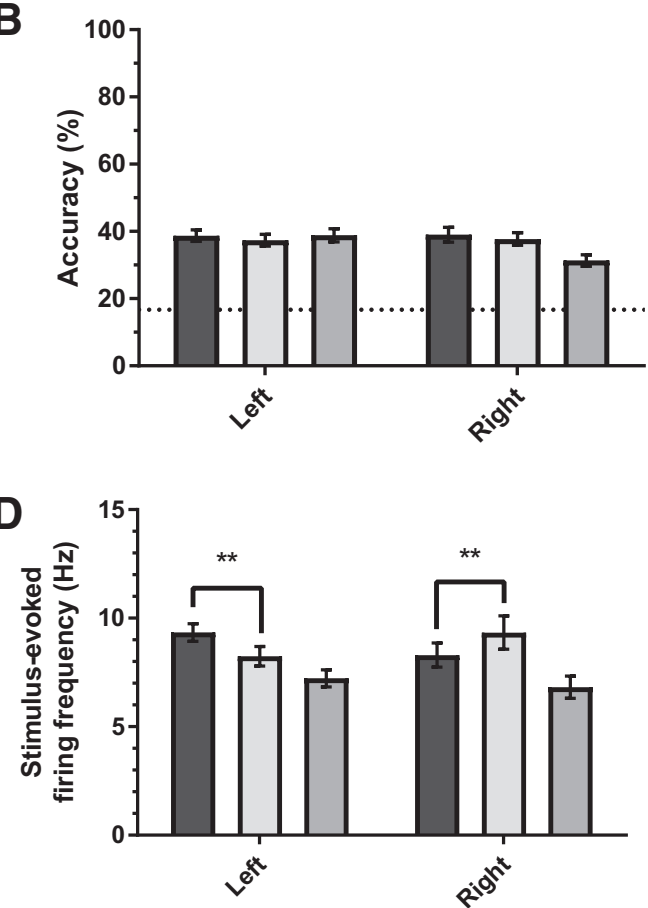

aCSF

E2

Washout

Figure 5. The effects of estradiol $\left(E_{2}\right)$ on auditory responsiveness in the NCM of sensorimotor-aged birds are lateralized. $\boldsymbol{A}, \boldsymbol{B}$, Depending on hemisphere, $\mathrm{E}_{2}$ treatment either increases (right NCM) or decreases (left NCM) auditory z-scores relative to aCSF (Trial 1) in sensorimotor subjects. However, classification accuracy remains unaffected $(\boldsymbol{B})$. $\boldsymbol{C}, \boldsymbol{D}$, Similar to $z$-scores, both spontaneous $(\boldsymbol{C})$ and stimulus-evoked $(\boldsymbol{D})$ firing rates decrease or increase in response to $\mathrm{E}_{2}$ depending on hemisphere (left or right $\mathrm{NCM}$, respectively). Dotted-line in $\boldsymbol{B}$ is chance-level prediction for classifier ( 1 in 6 chance for accurately classifying a given stimulus $=$ 16.67\%). $* p<0.05$ (left/right: Trial 1 vs. Trial 2); $* * p<0.01$ (left/right: Trial 1 vs. Trial 2).

However, the descriptive data suggest that $\mathrm{E}_{2}$ 's overall effect on accuracy was influenced by effects in right NCM (Fig. 4B; a main effect of hemisphere was nonsignificant, $p=0.067$ ). All other main effects and interactions for stimulus and hemisphere were nonsignificant across all physiologic and classification measurements for sensoryaged subjects $(p>0.80)$.

We noted a general trend for attenuated firing rates and $z$-scores across trials for sensory-aged subjects (e.g., compare washout to pre in Fig. 4). Therefore, in a separate set of sensory-aged birds ( $n=5$ birds; 6 single units), we tested whether observed decreases in neural activity also occurred in the absence of $E_{2}$ treatment. To this end, aCSF was administered across all 3 trials in place of $E_{2}$ and a washout trial (Trials 2 and 3 , respectively), and resulting activity was compared between Trials 1 and 2 . Normalized auditory responses decreased across trials (Fig. $4 A$, inset), but this was not statistically significant $\left(F_{(1,30)}=3.542, p=0.070 ; \eta^{2}=0.106\right.$; Trial 1 aCSF $=$ $0.41 \pm 0.03$; Trial 2 aCSF $=0.34 \pm 0.04$ ), nor were changes in spontaneous firing rates $\left(F_{(1,30)}=0.473, p=\right.$ $0.497 ; \eta^{2}=0.016$; Trial $1 \mathrm{aCSF}=2.55 \pm 0.15 \mathrm{~Hz}$; Trial 2 aCSF $=2.37 \pm 0.26 \mathrm{~Hz}$ ). However, there was an overall significant decrease in stimulus-evoked firing $\left(F_{(1,30)}=\right.$ $5.095, p=0.031 ; \eta^{2}=0.145 ;$ Trial $1 \mathrm{aCSF}=7.44 \pm 0.56$ $\mathrm{Hz}$; Trial $2 \mathrm{aCSF}=5.92 \pm 0.78 \mathrm{~Hz})$, and classification accuracy $\left(F_{(1,30)}=17.075, p<0.001 ; \eta^{2}=0.363\right.$; Trial 1
$\mathrm{aCSF}=47.92 \pm 3.21 \%$; Trial $2 \mathrm{aCSF}=36.55 \pm 2.56 \%)$ across Trials 1 and 2 . There were no significant stimulus * trial interactions or any overall effects of stimulus $(p>$ $0.10)$. Together, results from sensory-aged birds suggest that whereas $E_{2}$ may dampen auditory responsiveness in $\mathrm{NCM}$, this pattern is difficult to disentangle from overall decreases in neuronal firing and classification accuracy in rundown trials with aCSF only.

\section{Estradiol imparts hemisphere-dependent changes in sensorimotor-aged subjects}

For sensorimotor-aged subjects, there was a significant trial $*$ hemisphere interaction for $z$-score $\left(F_{(1,202)}=4.435\right.$, $p=0.036 ; \eta^{2}=0.021$; Fig. $5 A$ ), such that $E_{2}$ significantly reduced $z$-scores in the left $\left(F_{(1,112)}=4.845, p=0.030\right.$; $\left.\eta^{2}=0.041\right)$ but not in the right $\left(F_{(1,90)}=2.131, p=0.148\right.$; $\left.\eta^{2}=0.023\right)$ hemisphere. Further, $E_{2}$ imparted a hemisphere-dependent effect on firing rates in sensorimotoraged subjects (spontaneous: $F_{(1,202)}=6.594, p=0.011$; $\eta^{2}=0.032$; stimulus-evoked: $F_{(1,202)}=9.426, p=0.002$, $\eta^{2}=0.045$; Fig. $5 C, D$ ). Specifically, $E_{2}$ significantly decreased both spontaneous and stimulus-evoked firing in left NCM (spontaneous: $p=0.023 ; \eta^{2}=0.045$; stimulus: $\left.F_{(1,112)}=8.066, p=0.005 ; \eta^{2}=0.067\right)$, whereas overall firing rates in right NCM were significantly increased (spontaneous: $p=0.011 ; \eta^{2}=0.069$; stimulus-evoked: $\left.F_{(1,90)}=7.226, p=0.009, \eta^{2}=0.074\right)$. Classification 
Table 2. Stimulus-specific effects on single-unit NCM auditory responsiveness

\begin{tabular}{|c|c|c|c|c|c|c|}
\hline $\begin{array}{l}\text { Dependent variable (single-unit data) } \\
\text { Development (aCSF; Trial } 1 \text { only) }\end{array}$ & Model & Statistical tests & $\begin{array}{l}F \text {-values and degrees } \\
\text { of freedom }\end{array}$ & $p$-value & $\begin{array}{l}\text { Effect size } \\
\left(\text { partial } \eta^{2}\right)\end{array}$ & Post hoc results \\
\hline$z$-score & $\begin{array}{l}\text { Phase } \times \text { hemisphere } \times \\
\text { stimulus }\end{array}$ & $\begin{array}{c}\text { Three-way ANOVA; } \\
\text { Tukey's HSD }\end{array}$ & $F_{(7,292)}=4.682$ & $<0.001$ & 0.101 & $\begin{array}{l}\text { WN }<\text { CON1, CON2, HET, } \\
\text { JUV CON, and JUV } \\
\text { REV CON }(p<0.003)\end{array}$ \\
\hline Stimulus-evoked firing & $\begin{array}{l}\text { Phase } \times \text { hemisphere } \times \\
\text { stimulus }\end{array}$ & $\begin{array}{c}\text { Three-way ANOVA; } \\
\text { Tukey's HSD }\end{array}$ & $F_{(7,292)}=2.400$ & 0.022 & 0.054 & $\begin{array}{l}\text { WN }<\text { CON1 and HET } \\
\quad(p<0.022)\end{array}$ \\
\hline Classification accuracy & $\begin{array}{l}\text { Phase } \times \text { hemisphere } \times \\
\text { stimulus }\end{array}$ & $\begin{array}{l}\text { Three-way ANOVA; } \\
\text { Tukey's HSD }\end{array}$ & $F_{(7,262)}=2.529$ & 0.016 & 0.063 & WN $<$ JUV CON $(p=0.023)$ \\
\hline \multicolumn{7}{|l|}{ Effect of E2 (aCSF vs. E2) } \\
\hline \multicolumn{7}{|l|}{ Sensory } \\
\hline$z$-score & $\begin{array}{l}\text { Trial } \times \text { hemisphere } \times \\
\text { stimulus }\end{array}$ & Three-way ANOVA & $F_{(5,72)}=2.062$ & 0.080 & 0.125 & $\mathrm{n} / \mathrm{a}$ \\
\hline Stimulus-evoked firing & $\begin{array}{l}\text { Trial } \times \text { hemisphere } \times \\
\text { stimulus }\end{array}$ & Three-way ANOVA & $F_{(5,72)}=1.495$ & 0.202 & 0.094 & $\mathrm{n} / \mathrm{a}$ \\
\hline Classification accuracy & $\begin{array}{l}\text { Trial } \times \text { hemisphere } \times \\
\quad \text { stimulus }\end{array}$ & Three-way ANOVA & $F_{(1,54)}=1.298$ & 0.278 & 0.107 & $\mathrm{n} / \mathrm{a}$ \\
\hline \multicolumn{7}{|l|}{ Sensorimotor } \\
\hline \multicolumn{7}{|l|}{$z$-score } \\
\hline Left NCM & Trial $\times$ stimulus & $\begin{array}{l}\text { Two-way ANOVA; } \\
\text { Tukey's HSD }\end{array}$ & $F_{(7,112)}=3.097$ & 0.005 & 0.162 & $\begin{array}{l}\mathrm{WN}<\mathrm{BOS}, \mathrm{CON} 1, \mathrm{CON} 2 \\
\text { and HET }(p<0.038)\end{array}$ \\
\hline Right NCM & Trial $\times$ stimulus & Two-way ANOVA & $F_{(5,90)}=2.275$ & 0.054 & 0.112 & $\mathrm{n} / \mathrm{a}$ \\
\hline \multicolumn{7}{|l|}{ Stimulus-evoked firing } \\
\hline Left NCM & Trial $\times$ stimulus & Two-way ANOVA & $F_{(7,112)}=1.365$ & 0.227 & 0.079 & $\mathrm{n} / \mathrm{a}$ \\
\hline Right NCM & Trial $\times$ stimulus & Two-way ANOVA & $F_{(5,90)}=0.558$ & 0.732 & 0.030 & $\mathrm{n} / \mathrm{a}$ \\
\hline \multicolumn{7}{|l|}{ Classification accuracy } \\
\hline Left NCM & Trial $\times$ stimulus & $\begin{array}{l}\text { Two-way ANOVA; } \\
\text { Tukey's HSD }\end{array}$ & $F_{(7,112)}=2.415$ & 0.024 & 0.131 & WN $<$ JUV CON $(p=0.048)$ \\
\hline Right NCM & Trial $\times$ stimulus & Two-way ANOVA & $F_{(5,90)}=0.880$ & 0.498 & 0.047 & $\mathrm{n} / \mathrm{a}$ \\
\hline
\end{tabular}

n/a, not applicable.

accuracy was statistically unaffected by $E_{2}$ treatment $\left(F_{(1,202)}=3.369, p=0.068, \eta^{2}=0.016\right.$; Fig. $\left.5 B\right)$. In summary, these data suggest that acute modulation of NCM auditory responsiveness by $E_{2}$ is lateralized, and that $E_{2}$ in the right hemisphere of NCM enhances overall neural firing, independent of changes in stimulus coding in sensorimotor-aged birds, whereas the opposite is observed in left NCM.

\section{Naturalistic sounds elicit higher single-unit auditory responses in NCM across age}

In addition to developmental and $E_{2}$ effects on NCM auditory physiology, we compared stimulus-dependent effects on single-unit auditory responsiveness. As work on physiologic preference for natural sounds over synthetic tones in telencephalic auditory forebrain nuclei has been previously reported in several oscine species (Leppelsack and Vogt, 1976; Bonke et al., 1979), including zebra finches (Theunissen et al., 2004; Hauber et al., 2007), we report all the main effects of stimulus in Table 2 for concision. In short, we found that NCM is typically more responsive to naturalistic auditory stimuli (song) compared with a synthetic sound (white noise).

\section{Discussion}

Here, we demonstrate that auditory neurons in presinging, sensory-aged male zebra finches have higher auditory responses to natural communication vocalizations compared with older juvenile males. Moreover, sensitivities to $E_{2}$ signaling in auditory cortex change with age: although sensory-aged birds showed an overall decrease in auditory response when treated with $E_{2}$, sensorimotor-aged birds showed a divergent response to
$E_{2}$ depending on hemisphere (either overall increase or decrease). Taken together, this study is the first to our knowledge to consider developmental and hemispheric effects on sensory coding and rapid steroid modulation of auditory processing.

\section{Ontogenetic shifts in vocal communication encoding}

During the critical period phase for auditory memory formation, pre-singing (sensory-aged) juvenile songbirds encode communication signals with higher fidelity than juveniles beginning autogenous song production (sensorimotor-aged). As such, elevated auditory-evoked responses in sensory-aged birds suggest the transition from purely auditory encoding (sensory phase) to song production with gradual modification through error-correction (sensorimotor phase) learning may track these perceptual developmental shifts. To our knowledge, this is one of the first studies to document neurophysiological changes in the NCM of presinging and sensorimotor learning in juvenile male songbirds. Prior studies have described developmental shifts in the auditory forebrain but have mainly compared 20versus 35-dph songbirds (all sensory-aged). Amin et al. (2007) described adult-like auditory responses in the brainstem of 20- and 35-dph zebra finches and stimulusdependent auditory selectivity in the CMM of 35-dph birds. In awake recordings of NCM, electrophysiological auditory responses are comparable at 20 and 30-35 dph (Stripling et al., 2001; Miller-Sims and Bottjer, 2014). Our results build on these findings by expanding the span of time considered during the critical period. These findings inform how learning-dependent transitions during maturation shift auditory processing within NCM. 
The elevated auditory processing we observe in sensory-aged subjects may be related to the coincident formation of a tutor auditory memory during this critical period of development. Although auditory input is necessary during the song refinement and error-correction phase in sensorimotor-aged birds (e.g., Mandelblat-Cerf et al., 2014); initially, birds must solely listen before they sing. Perhaps enhanced auditory activity and encoding in NCM during early development ensures a high-fidelity tutor song memory acquisition for young males to subsequently imitate. As NCM is one of the putative loci for tutor song memory (Bolhuis and Gahr, 2006; London and Clayton, 2008; Gobes et al., 2010), elevated auditory responsiveness may be important for early tutor memory consolidation. Alternatively, an increasing amount of tutor experience may facilitate neural transitions from a more broadly tuned auditory circuit (sensory-aged; higher auditory neural activity) to a more selectively tuned circuit (sensorimotor-aged; relatively dampened auditory response). Yanagihara and Yazaki-Sugiyama (2016) found that a relatively short period of tutoring (10 days) radically shifted a subpopulation of single neurons' auditory selectivity in the NCM of juvenile males and biased neuronal responses primarily toward the tutor and/or birds' own song. If tutoring experience itself shapes auditory selectivity, then perhaps less experience with tutor or exposure to adult song in general in sensory-aged subjects ( $9 \mathrm{~d}$ relative to onset of critical period opening) compared to older juveniles (15-70 d) explains heightened auditory responsiveness in NCM. However, our finding that stimulus classification accuracy is higher in sensory-aged subjects suggests that rather than NCM being broadly tuned to any sound, young juvenile songbirds can accurately distinguish naturalistic communication signals with higher fidelity than sensorimotor-aged birds.

One caveat to our interpretation that there is a neural "switch point" in auditory processing that precisely tracks behavioral transitions during vocal learning (sensory/presinging to sensorimotor/singing) is the ability to dissociate true developmental effects from $\mathrm{E}_{2}$-dependent effects. In adult songbirds, song presentation elicits an increase in $\mathrm{E}_{2}$ levels in NCM, whereas in juveniles, tutoring leads to decreased $E_{2}$ in NCM and increased levels afterward (Remage-Healey et al., 2008, 2012; Chao et al., 2015). As such, auditory presentations alone may elicit changes in local $E_{2}$ availability that may be age-dependent. However, it remains to be tested whether song presentations to anesthetized songbirds, such as in our study, drive local changes in $\mathrm{E}_{2}$ production as with awake, behaving songbirds. Thus, future experiments should clarify whether local $E_{2}$ synthesis in NCM is state-dependent, and should also explore whether local infusion of an aromatase inhibitor during song presentation blocks or unmasks agedependent and estradiol-dependent regulation of auditory responsiveness in NCM.

Future experiments should also consider these identified developmental milestones in the NCM of juvenile females, who also learn song early posthatching for eventual mate selection in adulthood (Miller, 1979; Riebel, 2000; Terpstra et al., 2006). The extent that elevated auditory responses in NCM of sensory-aged juveniles are similar between males and females will contribute information about its underlying mechanism.

\section{Acute effects of estrogens on sensory-aged songbirds}

Sensory-aged male zebra finches begin forming auditory memories of their tutor's song before attempting their own vocalizations (Mooney, 2009). As such, we predicted that $E_{2}$ would enhance auditory tuning as it does in adults (Remage-Healey et al., 2010, 2012; Pinaud and Tremere, 2012; Remage-Healey and Joshi, 2012; but see Lattin et al., 2017). However, $E_{2}$ treatments led to significant decrements in auditory processing irrespective of hemisphere. One explanation may be that $E_{2}$ dynamics change during development. Chao et al. (2015) observed acute decreases in $\mathrm{E}_{2}$ levels during tutoring in the NCM of developing male zebra finches, but also that $\mathrm{NCM} \mathrm{E}_{2}$ levels increase immediately after a tutoring session. As such, acute neuroestrogen production may impair auditory memory acquisition during a learning session in sensory-aged songbirds (Korol and Pisani, 2015; Rensel et al., 2015), whereas post-training $\mathrm{E}_{2}$ increases may facilitate memory consolidation (Srivastava et al., 2013; Frick, 2015; Vahaba and Remage-Healey, 2015). Further, the expression of telencephalic GPER1 (G-protein coupled estrogen receptor 1 that can mediate rapid neuroestrogen signaling [Rudolph et al., 2016]) is five-fold higher in sensory-aged zebra finches (Acharya and Veney, 2011). Therefore, NCM may be particularly sensitive to low concentrations of $E_{2}$ in sensory-aged animals. This work thus suggests that dynamic changes in estrogen receptor and aromatase protein expression in NCM across development may explain an initial suppressive effect of $E_{2}$ signaling on auditory processing in sensoryaged male songbirds.

One important caveat to these results is that in a separate set of sensory-aged birds with aCSF retrodialyzed across all three trials (run-down experiment), we observed decreased classification accuracy and stimulus-evoked firing rates, as well as a trend for reduced normalized auditory responsiveness. These results make it more difficult to disentangle the effects of $E_{2}$ on decreases in NCM responsiveness and encoding in sensory-aged subjects from purely time-dependent effects. Nonetheless, $E_{2}$ reduced spontaneous firing in sensory-aged birds, which was not observed in aCSF-only trials, and may reflect a true dampening of auditory responsiveness. Moreover, the run-down experiment emphasizes how our observations of increased firing during $\mathrm{E}_{2}$ treatment, as seen in the right NCM of sensorimotor-aged subjects, are likely counteracting this overall steady run-down effect in juvenile males.

\section{Acute, lateralized effects of estrogens on sensorimotor-aged songbirds}

The lateralization of $E_{2}$ actions on auditory encoding and firing rate in NCM differ across development. In sensorimotor-aged birds, $\mathrm{E}_{2}$ imparts a hemisphere-dependent effect. In left NCM, $E_{2}$ led to decreased normalized auditory response, as well as spontaneous and stimulus-evoked firing rates, without affecting classification accuracy. In 
contrast, $\mathrm{E}_{2}$ administration in the right $\mathrm{NCM}$ increased stimulus and spontaneous-evoked firing rates, without impacting normalized auditory responses or classification accuracy. These data add to a growing literature on the lateralized neuromodulation of hearing by brain hormones. For example, oxytocin receptors are preferentially upregulated the in left auditory cortex of maternal female rats, which enhances pup call saliency/encoding (Marlin et al., 2015). In male European starlings, inhibiting aromatase suppresses vocal communication responses in the left, but not right, hemisphere of the auditory forebrain (De Groof et al., 2017). Similarly, blocking $E_{2}$ synthesis in left but not right NCM extinguishes male songbirds' behavioral preference for their own song (Remage-Healey et al., 2010). Therefore, our findings add further evidence for hemisphere-dependent hormone neuromodulation of communication processing in auditory cortex, and expand this concept to include developing animals.

Prior work on developmental neuromodulation has not addressed how sensitivities to $\mathrm{E}_{2}$ may differ by hemisphere, and whether estrogen synthase or estrogen receptor expression is similarly lateralized. Chao et al. (2015) found decreased $E_{2}$ in NCM during tutor song exposure in developing male subjects; however, $\mathrm{E}_{2}$ was measured only within the left NCM. Therefore, our current results suggest that $\mathrm{E}_{2}$ fluctuations in right NCM may increase or remain unchanged during tutoring. Future experiments should also clarify changes in aromatase and estrogen receptors (both nuclear [ER $\alpha$ and $\mathrm{ER} \beta]$ and membrane-bound [GPER1; mGluR1/ER $\alpha$ ]) across development and between hemispheres, as these factors may also account for divergent effects of $E_{2}$ on auditory physiology in NCM across the critical period. Alternatively, the auditory cortex of juvenile male zebra finches may mature at different rates depending on hemisphere. Our data suggest that the right $\mathrm{NCM}$ matures faster than the left, as $\mathrm{E}_{2}$ enhancement of auditory responsiveness is more adult-like in the right versus left NCM of sensorimotor-aged subjects (Remage-Healey et al., 2010). Future experiments exploring developmental changes should also identify whether NCM is lateralized in neuronal development across the critical period, as well, since there are no reported differences in NCM cell density between developing versus adult male NCM (Stripling et al., 2001), nor any published quantifications of left versus right neuronal density in $\mathrm{NCM}$ at any age.

These findings contribute to a broader point of interest on how steroid hormones may participate in learning. Accumulating evidence demonstrate that rapid, local $\mathrm{E}_{2}$ synthesis and signaling is critically linked to neural plasticity in the hippocampus and amygdala (Zhao et al., 2010; Srivastava et al., 2013; Bailey et al., 2017; Bender et al., 2017). Less is known about rapid $E_{2}$ signaling and plasticity in sensory cortices, such as the auditory cortex. In adult zebra finches, blocking global $E_{2}$ synthesis impairs neural adaptation to familiar songs in NCM, a proxy for auditory memory formation (Yoder et al., 2012). In juvenile songbirds, circulating $\mathrm{E}_{2}$ predicts tutor imitation accuracy (Marler et al., 1987); however, the majority of studies on hormones and song learning in development have focused on androgens. Administering testosterone or dihydrotestosterone to juvenile songbirds prematurely crystallizes song (Korsia and Bottjer, 1991; Bottjer and Hewer, 1992; Whaling et al., 1995; Livingston and Mooney, 2001; however, see Templeton et al., 2012). Therefore, it remains to be tested how neuroestrogen synthesis in the auditory forebrain is involved in vocal learning. Our results suggest that local $E_{2}$ may interfere with auditory encoding in sensory-aged birds and within the left NCM of sensorimotor-aged birds, whereas $\mathrm{E}_{2}$ in the right $\mathrm{NCM}$ in sensorimotor-aged animals may aid in encoding song. These possibilities await future experimental tests to determine potential functional roles for $E_{2}$ in song learning.

\section{Conclusion}

Here, we demonstrate that robust shifts in sensory processing in the auditory cortex precisely track experiencedependent critical period milestones, and extend our understanding of estrogen-dependent neuromodulation of auditory responsiveness across development. Our findings indicate that age and hemisphere are critical factors to consider when evaluating sensory physiology in development and in response to neuromodulators. Further, these data provide insight into a broader understanding of how estrogen signaling and audition may change across the lifespan, and in relation to hemisphere and communication learning. In humans, estrogens generally enhance hearing in adulthood, and appear to have a lateralized effect on listening (Tillman, 2010) and verbal memory (Fernandez et al., 2003). Interestingly, Wild et al. (2017) found adult-like neural responses to speech in the auditory cortex of 3- and 9-month-old infants, a time during which circulating estrogen levels predict future language success (Wermke et al., 2014; Quast et al., 2016). As such, future research should consider both hormonal state and hemisphere when studying hearing-evoked neural changes in auditory cortex.

\section{References}

Acharya KD, Veney SL (2011) Characterization of the G-proteincoupled membrane-bound estrogen receptor GPR30 in the zebra finch brain reveals a sex difference in gene and protein expression. Dev Neurobiol 72:1433-1446.

Adkins-Regan E, Abdelnabi M, Mobarak M, Ottinger MA (1990) Sex steroid levels in developing and adult male and female zebra finches (Poephila guttata). Gen Comp Endocrinol 78:93-109. Medline

Adret P, Meliza CD, Margoliash D (2012) Song tutoring in presinging zebra finch juveniles biases a small population of higher-order song-selective neurons toward the tutor song. J Neurophysiol 108:1977-1987. CrossRef

Amin N, Doupe A, Theunissen FE (2007) Development of selectivity for natural sounds in the songbird auditory forebrain. J Neurophysiol 97:3517-3531. CrossRef Medline

Avey MT, Phillmore LS, MacDougall-Shackleton SA (2005) Immediate early gene expression following exposure to acoustic and visual components of courtship in zebra finches. Behav Brain Res 165:247-253. CrossRef Medline

Bailey DJ, Wade J (2003) Differential expression of the immediate early genes FOS and ZENK following auditory stimulation in the juvenile male and female zebra finch. Brain Res Mol Brain Res 116:147-154. Medline

Bailey DJ, Wade J (2005) FOS and ZENK responses in 45-day-old zebra finches vary with auditory stimulus and brain region, but not sex. Behav Brain Res 162:108-115. CrossRef 
Bailey DJ, Makeyeva YV, Paitel ER, Pedersen AL, Hon AT, Gunderson JA, Saldanha CJ (2017) Hippocampal aromatization modulates spatial memory and characteristics of the synaptic membrane in the male zebra finch. Endocrinology 158:852-859. CrossRef Medline

Bender RA, Zhou L, Vierk R, Brandt N, Keller A, Gee CE, Schäfer MK, Rune GM (2017) Sex-dependent regulation of aromatase-mediated synaptic plasticity in the basolateral amygdala. J Neurosci 37:15321545. CrossRef Medline

Böhner J (1990) Early acquisition of song in the zebra finch, Taeniopygia guttata. Anim Behav 39:369-374. CrossRef

Bolhuis JJ (1991) Mechanisms of avian imprinting: a review. Biol Rev Camb Philos Soc 66:303-345. Medline

Bolhuis JJ, Gahr M (2006) Neural mechanisms of birdsong memory. Nat Rev Neurosci 7:347-357. CrossRef Medline

Bonke D, Scheich H, Langner G (1979) Responsiveness of units in the auditory neostriatum of the guinea fowl (Numida meleagris) to species-specific calls and synthetic stimuli. J Comp Physiol 132: 257-276. CrossRef

Bottjer SW, Hewer SJ (1992) Castration and antisteroid treatment impair vocal learning in male zebra finches. J Neurobiol 23:337353. CrossRef Medline

Braaten RF, Petzoldt M, Colbath A (2006) Song perception during the sensitive period of song learning in zebra finches (Taeniopygia guttata). J Comp Psychol 120:79-88. CrossRef Medline

Brainard MS, Doupe AJ (2013) Translating birdsong: songbirds as a model for basic and applied medical research. Ann Rev Neurosci 36:489-517. CrossRef Medline

Canopoli A, Herbst JA, Hahnloser RH (2014) A higher sensory brain region is involved in reversing reinforcement-induced vocal changes in a songbird. J Neurosci 34:7018-7026. CrossRef

Caras ML, O'Brien M, Brenowitz EA, Rubel EW (2012) Estradiol selectively enhances auditory function in avian forebrain neurons. J Neurosci 32:17597-17611. CrossRef Medline

Caras ML, Sen K, Rubel EW, Brenowitz EA (2015) Seasonal plasticity of precise spike timing in the avian auditory system. J Neurosci 35:3431-3445. CrossRef Medline

Chao A, Paon A, Remage-Healey L (2015) Dynamic variation in forebrain estradiol levels during song learning. Dev Neurobiol 75: 271-286. CrossRef Medline

Chew SJ, Mello C, Nottebohm F, Jarvis E, Vicario DS (1995) Decrements in auditory responses to a repeated conspecific song are long-lasting and require two periods of protein synthesis in the songbird forebrain. Proc Natl Acad Sci U S A 92:3406-3410. Medline

Clayton DF (2013) The genomics of memory and learning in songbirds. Ann Rev Genomics Hum Genet 14:45-65. CrossRef Medline

Cohen J (1988) Statistical Power Analysis for the Behavioral Sciences. Hillsdale, NJ.: L. Erlbaum Associates.

Colombelli-Négrel D, Hauber ME, Robertson J, Sulloway FJ, Hoi H, Griggio M, Kleindorfer S (2012) Embryonic learning of vocal passwords in superb fairy-wrens reveals intruder cuckoo nestlings. Curr Biol: CB 22:2155-2160. CrossRef Medline

De Groof G, Balthazart J, Cornil CA, Van der Linden A (2017) Topography and lateralized effect of acute aromatase inhibition on auditory processing in a seasonal songbird. J Neurosci 37:42434254. CrossRef

De Groof G, Poirier C, George I, Hausberger M, Van der Linden A (2013) Functional changes between seasons in the male songbird auditory forebrain. Front Behav Neurosci 7:196. CrossRef Medline

Fernández G, Weis S, Stoffel-Wagner B, Tendolkar I, Reuber M, Beyenburg S, Klaver P, Fell J, de Greiff A, Ruhlmann J, Reul J, Elger CE (2003) Menstrual cycle-dependent neural plasticity in the adult human brain is hormone, task, and region specific. J Neurosci 23:3790-3795. Medline

Frick KM (2015) Molecular mechanisms underlying the memoryenhancing effects of estradiol. Horm Behav 74:4-18. CrossRef Medline

Gobes SM, Zandbergen MA, Bolhuis JJ (2010) Memory in the making: localized brain activation related to song learning in young songbirds. Proc Biol Sci 277:3343-3351. CrossRef Medline
Griffiths R, Double MC, Orr K, Dawson RJ (1998) A DNA test to sex most birds. Mol Ecol 7:1071-1075. Medline

Hauber ME, Cassey P, Woolley SM, Theunissen FE (2007) Neurophysiological response selectivity for conspecific songs over synthetic sounds in the auditory forebrain of non-singing female songbirds. J Comp Physiol A Neuroethol Sens Neural Behav Physiol Neuroethol Sens Neural Behav Physiol 193:765-774. CrossRef Medline

Hensch TK (2005) Critical period plasticity in local cortical circuits. Nat Rev Neurosci 6:877-888. CrossRef Medline

Immelmann K (1969) Song development in the zebra finch and other estrildid finches. In: Bird Vocalizations (Thorpe WH, ed); Cambridge, UK: Cambridge University Press.

Jin H, Clayton DF (1997) Localized changes in immediate-early gene regulation during sensory and motor learning in zebra finches. Neuron 19:1049-1059. CrossRef

Konishi M (1965) The role of auditory feedback in the control of vocalization in the white-crowned sparrow. Zeitschr Tierpsychol 22:770-783. Medline

Korol DL, Pisani SL (2015) Estrogens and cognition: friends or foes? An evaluation of the opposing effects of estrogens on learning and memory. Horm Behav 74:105-115. CrossRef Medline

Korsia S, Bottjer SW (1991) Chronic testosterone treatment impairs vocal learning in male zebra finches during a restricted period of development. J Neurosci 11:2362-2371. Medline

Kuhl PK (2010) Brain mechanisms in early language acquisition. Neuron 67:713-727. CrossRef Medline

Lattin CR, Stabile FA, Carson RE (2017) Estradiol modulates neural response to conspecific and heterospecific song in female house sparrows: an in vivo positron emission tomography study. PLoS One 12:e0182875. CrossRef

Lee V, Pawlisch BA, Macedo-Lima M, Remage-Healey L (2017) Norepinephrine enhances song responsiveness and encoding in the auditory forebrain of male zebra finches. J Neurophysiol 00251 02017.

Leppelsack HJ, Vogt M (1976) Responses of auditory neurons in the forebrain of a songbird to stimulation with species-specific sounds. J Comp Physiol 107:263-274. CrossRef

Livingston FS, Mooney R (2001) Androgens and isolation from adult tutors differentially affect the development of songbird neurons critical to vocal plasticity. J Neurophysiol 85:34-42. Medline

London SE, Clayton DF (2008) Functional identification of sensory mechanisms required for developmental song learning. Nat Neurosci 11:579-586. CrossRef Medline

Lorenz KZ (1937) The companion in the bird's world. Auk 54:245273. CrossRef

Mandelblat-Cerf Y, Las L, Denisenko N, Fee MS (2014) A role for descending auditory cortical projections in songbird vocal learning. eLife 3:e02152. CrossRef

Maney DL, Cho E, Goode CT (2006) Estrogen-dependent selectivity of genomic responses to birdsong. Eur J Neurosci 23:1523-1529. CrossRef Medline

Marler P, Peters S, Wingfield J (1987) Correlations between song acquisition, song production, and plasma levels of testosterone and estradiol in sparrows. J Neurobiol 18:531-548. CrossRef Medline

Marler P, Peters S, Ball GF, Dufty AM, Jr, Wingfield JC (1988) The role of sex steroids in the acquisition and production of birdsong. Nature 336:770-772. CrossRef Medline

Marlin BJ, Mitre M, D'Amour JA, Chao MV, Froemke RC (2015) Oxytocin enables maternal behaviour by balancing cortical inhibition. Nature 520:499-504. CrossRef Medline

Mello CV, Vicario DS, Clayton DF (1992) Song presentation induces gene expression in the songbird forebrain. Proc Natl Acad Sci U S A 89:6818-6822. Medline

Metzdorf R, Gahr M, Fusani L (1999) Distribution of aromatase, estrogen receptor, and androgen receptor mRNA in the forebrain of songbirds and nonsongbirds. J Comp Neur 407:115-129. Medline 
Miller-Sims VC, Bottjer SW (2014) Development of neural responsivity to vocal sounds in higher level auditory cortex of songbirds. J Neurophysiol 112:81-94. CrossRef Medline

Miller DB (1979) Long-term recognition of father's song by female zebra finches. Nature 280:389-391. CrossRef

Mooney R (2009) Neural mechanisms for learned birdsong. Learn Mem 16:655-669. CrossRef Medline

Moorman S, Gobes SM, van de Kamp FC, Zandbergen MA, Bolhuis JJ (2015) Learning-related brain hemispheric dominance in sleeping songbirds. Sci Rep 5:9041. CrossRef Medline

Moorman S, Gobes SM, Kuijpers M, Kerkhofs A, Zandbergen MA, Bolhuis JJ (2012) Human-like brain hemispheric dominance in birdsong learning. Proc Natl Acad Sci U S A 109:12782-12787. CrossRef Medline

Pawlisch BA, Remage-Healey L (2015) Neuroestrogen signaling in the songbird auditory cortex propagates into a sensorimotor network via an 'interface' nucleus. Neuroscience 284:522-535. CrossRef Medline

Peterson RS, Yarram L, Schlinger BA, Saldanha CJ (2005) Aromatase is pre-synaptic and sexually dimorphic in the adult zebra finch brain. Proc Biol Sci 272:2089-2096. CrossRef Medline

Petkov Cl, Jarvis ED (2012) Birds, primates, and spoken language origins: behavioral phenotypes and neurobiological substrates. Front Evol Neurosci 4:12. CrossRef Medline

Pinaud R, Tremere LA (2012) Control of central auditory processing by a brain-generated oestrogen. Nat Rev Neurosci 13:521-527. CrossRef Medline

Pröve E (1983) Hormonal correlates of behavioural development in male zebra finches. In: Hormones and Behaviour in Higher Vertebrates (Balthazart J, Pröve E, Gilles R, eds). New York: Springer.

Quast A, Hesse V, Hain J, Wermke P, Wermke K (2016) Baby babbling at five months linked to sex hormone levels in early infancy. Infant Behav Dev 44:1-10. CrossRef Medline

Remage-Healey L, Joshi NR (2012) Changing neuroestrogens within the auditory forebrain rapidly transform stimulus selectivity in a downstream sensorimotor nucleus. J Neurosci 32:8231-8241. CrossRef

Remage-Healey L, Maidment NT, Schlinger BA (2008) Forebrain steroid levels fluctuate rapidly during social interactions. Nat Neurosci 11:1327-1334. CrossRef Medline

Remage-Healey L, Coleman MJ, Oyama RK, Schlinger BA (2010) Brain estrogens rapidly strengthen auditory encoding and guide song preference in a songbird. Proc Natl Acad Sci U S A 107: 3852-3857. CrossRef

Remage-Healey L, Dong SM, Chao A, Schlinger BA (2012) Sexspecific, rapid neuroestrogen fluctuations and neurophysiological actions in the songbird auditory forebrain. J Neurophysiol 107: 1621-1631. CrossRef Medline

Rensel MA, Ellis JM, Harvey B, Schlinger BA (2015) Sex, estradiol, and spatial memory in a food-caching corvid. Horm Behav 75:4554. CrossRef Medline

Riebel K (2000) Early exposure leads to repeatable preferences for male song in female zebra finches. Roy Soc Lond B Bio 267:25532558. P CrossRef

Roberts TF, Gobes SM, Murugan M, Ölveczky BP, Mooney R (2012) Motor circuits are required to encode a sensory model for imitative learning. Nat Neurosci 15:1454-1459. CrossRef Medline

Rudolph LM, Cornil CA, Mittelman-Smith MA, Rainville JR, RemageHealey L, Sinchak K, Micevych PE (2016) Actions of steroids: new neurotransmitters. J Neurosci 36:11449-11458. CrossRef Medline

Saldanha CJ, Burstein SR, Duncan KA (2013) Induced synthesis of oestrogens by glia in the songbird brain. $\mathrm{J}$ Neuroendocrinol 25: 1032-1038. CrossRef Medline

Saldanha CJ, Tuerk MJ, Kim YH, Fernandes AO, Arnold AP, Schlinger BA (2000) Distribution and regulation of telencephalic aromatase expression in the zebra finch revealed with a specific antibody. J Comp Neur 423:619-630. Medline

Schneider DM, Woolley SM (2013) Sparse and background-invariant coding of vocalizations in auditory scenes. Neuron 79:141-152. CrossRef Medline
Schreiber S, Fellous JM, Whitmer D, Tiesinga P, Sejnowski TJ (2003) A new correlation-based measure of spike timing reliability. Neurocomputing 52-54:925-931. CrossRef Medline

Silverin B, Baillien M, Foidart A, Balthazart J (2000) Distribution of aromatase activity in the brain and peripheral tissues of passerine and nonpasserine avian species. Gen Comp Endocrinol 117:3453. CrossRef Medline

Srivastava DP, Woolfrey KM, Penzes P (2013) Insights into rapid modulation of neuroplasticity by brain estrogens. Pharmacol Rev 65:1318-1350. CrossRef Medline

Stripling R, Kruse AA, Clayton DF (2001) Development of song responses in the zebra finch caudomedial neostriatum: role of genomic and electrophysiological activities. J Neurobiol 48:163180. Medline

Tchernichovski O, Nottebohm F, Ho CE, Pesaran B, Mitra PP (2000) A procedure for an automated measurement of song similarity. Anim Behav 59:1167-1176. CrossRef Medline

Templeton CN, Burt JM, Campbell SE, Lent K, Brenowitz EA Beecher MD (2012) Immediate and long-term effects of testosterone on song plasticity and learning in juvenile song sparrows. Behav Proc 90:254-260. CrossRef Medline

Terpstra NJ, Bolhuis JJ, Riebel K, van der Burg JM, den Boer-Visser AM (2006) Localized brain activation specific to auditory memory in a female songbird. J Comp Neur 494:784-791. CrossRef

Theunissen FE, Amin N, Shaevitz SS, Woolley SM, Fremouw T, Hauber ME (2004) Song selectivity in the song system and in the auditory forebrain. Ann N Y Acad Sci 1016:222-245. CrossRef Medline

Thorpe WH (1954) The process of song-learning in the chaffinch as studied by means of the spectrograph. Nature 173:465-469. CrossRef

Tillman GD (2010) Estradiol levels during the menstrual cycle differentially affect latencies to right and left hemispheres during dichotic listening: an ERP study. Psychoneuroendocrinology 35: 249-261. CrossRef Medline

Vahaba DM, Remage-Healey L (2015) Brain estrogen production and the encoding of recent experience. Curr Opin Behav Sci 6:148153. CrossRef Medline

Vates GE, Broome BM, Mello CV, Nottebohm F (1996) Auditory pathways of caudal telencephalon and their relation to the song system of adult male zebra finches. J Comp Neur 366:613-642. CrossRef Medline

Wang Y, Brzozowska-Prechtl A, Karten HJ (2010) Laminar and columnar auditory cortex in avian brain. Proc Natl Acad Sci U S A 107:12676-12681. CrossRef Medline

Weichel K, Schwager G, Heid P, Güttinger HR, Pesch A (1986) Sex differences in plasma steroid concentrations and singing behaviour during ontogeny in canaries (Serinus canaria). Ethology 73: 281-294. CrossRef

Wermke K, Hain J, Oehler K, Wermke P, Hesse V (2014) Sex hormone influence on human infants' sound characteristics: melody in spontaneous crying. Biol Lett 10:20140095. CrossRef Medline

Whaling CS, Nelson DA, Marler P (1995) Testosterone-induced shortening of the storage phase of song development in birds interferes with vocal learning. Dev Psychobiol 28:367-376. CrossRef Medline

Wiesel TN, Hubel DH (1963) Single-cell responses in striate cortex of kittens deprived of vision in one eye. J Neurophysiol 26:1003-1017.

Wild CJ, Linke AC, Zubiaurre-Elorza L, Herzmann C, Duffy H, Han VK, Lee DSC, Cusack R (2017) Adult-like processing of naturalistic sounds in auditory cortex by $3-$ and 9 -month old infants. NeuroImage 157:623-634. CrossRef Medline

Yanagihara S, Yazaki-Sugiyama Y (2016) Auditory experiencedependent cortical circuit shaping for memory formation in bird song learning. Nat Commun 7:11946. CrossRef Medline

Yoder KM, Lu K, Vicario DS (2012) Blocking estradiol synthesis affects memory for songs in auditory forebrain of male zebra finches. Neuroreport 23:922-926. CrossRef Medline

Zhao Z, Fan L, Frick KM (2010) Epigenetic alterations regulate estradiol-induced enhancement of memory consolidation. Proc Natl Acad Sci U S A 107:5605-5610. CrossRef Medline 